\title{
A simple framework for modelling the photochemical response to solar spectral irradiance variability in the stratosphere
}

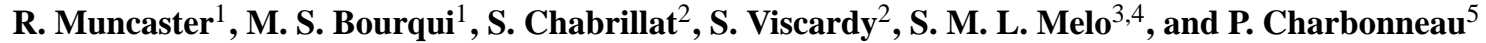 \\ ${ }^{1}$ McGill University, Montréal, Québec, Canada \\ ${ }^{2}$ Belgian Institute for Space Aeronomy, Brussels, Belgium \\ ${ }^{3}$ Canadian Space Agency, St. Hubert, Québec, Canada \\ ${ }^{4}$ Department of Physics, University of Toronto, Toronto, Ontario, Canada \\ ${ }^{5}$ Department of Physics, University of Montréal, Montréal, Québec, Canada
}

Correspondence to: M. S. Bourqui (michel.bourqui@mcgill.ca)

Received: 23 August 2011 - Published in Atmos. Chem. Phys. Discuss.: 9 December 2011

Revised: 1 August 2012 - Accepted: 10 August 2012 - Published: 23 August 2012

\begin{abstract}
The stratosphere is thought to play a central role in the atmospheric response to solar irradiance variability. Recent observations suggest that the spectral solar irradiance (SSI) variability involves significant time-dependent spectral variations, with variable degrees of correlation between wavelengths, and new reconstructions are being developed. In this paper, we propose a simplified modelling framework to characterise the effect of short term SSI variability on stratospheric ozone. We focus on the pure photochemical effect, for it is the best constrained one. The photochemical effect is characterised using an ensemble simulation approach with multiple linear regression analysis. A photochemical column model is used with interactive photolysis for this purpose. Regression models and their coefficients provide a characterisation of the stratospheric ozone response to SSI variability and will allow future inter-comparisons between different SSI reconstructions. As a first step in this study, and to allow comparison with past studies, we take the representation of SSI variability from the Lean (1997) solar minimum and maximum spectra. First, solar maximum-minimum response is analysed for all chemical families and partitioning ratios, and is compared with past studies. The ozone response peaks at $0.18 \mathrm{ppmv}$ (approximately $3 \%$ ) at $37 \mathrm{~km}$ altitude. Second, ensemble simulations are regressed following two linear models. In the simplest case, an adjusted coefficient of determination $\bar{R}^{2}$ larger than 0.97 is found throughout the stratosphere using two predictors, namely the previous day's ozone perturbation and the current day's solar irradiance perturbation. A better accuracy $\left(\bar{R}^{2}\right.$ larger than
\end{abstract}

0.9992) is achieved with an additional predictor, the previous day's solar irradiance perturbation. The regression models also provide simple parameterisations of the ozone perturbation due to SSI variability. Their skills as proxy models are evaluated independently against the photochemistry column model. The bias and RMS error of the best regression model are found smaller than $1 \%$ and $15 \%$ of the ozone response, respectively. Sensitivities to initial conditions and to magnitude of the SSI variability are also discussed.

\section{Introduction}

Solar variability has gained much attention over the past decade for its potential effect on the Earth climate and as a natural modulator of anthropogenic climate change. The detailed mechanisms involved in this modulation are currently not well understood. However, the stratosphere may play a central role, possibly through dynamical coupling with the troposphere (e.g. Egorova, 2005; Semeniuk et al., 2011). The stratosphere is most sensitive to the ultra-violet (UV) range of the solar spectrum. The magnitude of variability in the UV is wavelength-dependent and is between one and two orders of magnitude larger than the variability of the total solar irradiance (TSI). As a result, numerical models need to incorporate some spectral dependence in their representation of solar variability. Most past numerical studies have been performed with a representation of spectral solar irradiance (SSI) variability based upon pre-defined solar irradiance spectra, such 
as 11-yr solar maximum and minimum spectra or monthly spectra. The temporal SSI variability is then simply obtained by keeping the different wavelengths linearly related. Under this assumption of linear wavelength time variability, the photolysis can be simplified in CCMs to a linear combination of two pre-calculated photolysis look-up tables (e.g. Austin et al., 2007). This however ignores any decorrelation of variability between different wavelengths occurring on shorter time scales. Such decorrelations on time scales shorter than dynamical ones might have significant impacts.

However, the solar irradiance variability involves significant time-dependent spectral variations (where different wavelengths can be decorrelated) which is explained by the fact that different parts of the spectra are generated at different altitudes in the solar atmosphere that correspond to different conditions of temperature in the Sun (see DeLand and Cebula, 1993, and more recently Thuillier et al., 2012). Recent measurements of SSI by the Solar Radiation and Climate Experiment (SORCE) satellite showed disagreement with previous measurements (Harder et al., 2009). In particular, SORCE observations show three to five times more variability in UV radiation than predicted by proxy model. This opened a rich debate around SSI time series reconstructions.

As a consequence of this non-linear wavelength time dependence in the solar irradiance variability, CCMs might need to allow for arbitrary spectrally resolved irradiance variability (SPARC CCMVal, 2010). This however adds a large weight to the computational cost of CCMs and imposes stronger limits to their utilisation for long time periods. But robust separation of the response to solar variability from other sources of variability in Climate-Chemistry Models (CCMs) requires the simulation of time periods that are long enough to sufficiently reduce the large unforced variability. It remains to be determined how detailed a representation of solar variability is needed in CCMs in order to both assure reliability and keep CCMs appropriate for long simulations. In parallel, different approaches of reconstructing/modelling SSI time series are currently emerging (e.g. Thuillier et al., 2012; Bolduc et al., 2012) and need to be evaluated. Evaluation against solar observations is possible with some acceptable reliability for recent times (from 1978 on, e.g. DeLand and Cebula, 2008). An alternative approach is to evaluate the reconstructed/modelled SSI time series from the perspective of their effects on the stratosphere (e.g. Haigh et al., 2010; Merkel et al., 2011).

Here we propose a simple modelling framework to characterise the effect of SSI variability on the stratosphere. This framework will allow to evaluate and inter-compare the effect of different SSI reconstructions on the stratosphere. We focus on the pure photochemical response of the stratosphere to short-term solar variability. This response can not be directly compared to observations since it does not take into account dynamical and radiative feed-back. However, this pure photochemical response is well constrained and should have a high degree of similarity among numerical models. It therefore represents a robust step in the evaluation of SSI reconstructions from a stratospheric perspective. Although the focus is on short-term solar variability, the results are expected to be of relevance for long-term solar variability too, since the photochemical mechanisms are identical. We use a comprehensive photochemistry column model which includes a fully interactive photolysis scheme. In order to simulate the pure photochemical response, the chemistry is left to evolve alone with time as an initial condition problem, without any external sources/sinks nor any diffusion/advection representation. This imposes a transient chemistry approach with a limit to the duration of the numerical experiments of about ten days (see Sect. 2.2), after which the chemical concentrations have deviated away and are not relevant anymore for stratospheric purposes.

In order to characterise the effect of SSI variability on this time scale, we use an ensemble simulation approach. We perform large ensembles of 10-day simulations, each driven by an independent time series of daily-varying SSI. The number of simulations in the ensemble must be large to cover with enough detail the space of possible conditions. The effect of the SSI on stratospheric ozone is then captured statistically from the ensemble of simulations by using a multiple linear regression. Here, the multiple regression model needs to be carefully chosen such that it provides an as complete as possible characterisation of the ozone response. In this study, we test two regression models with two and three predictors, respectively. The simplest one has as predictors the solar irradiance perturbation on the current day and the concentration of ozone on the previous day. The most accurate one has in addition the irradiance perturbation of the previous day as predictor. The coefficients of the regression model provide a characterisation of the response of stratospheric ozone to the type of SSI variability reconstruction chosen. Intercomparison between different types of SSI variability reconstruction can then be done by simply comparing the regression coefficients and/or the results of the regression models in simple cases. For instance, the magnitude of the response to a 27-day cycle can be retrieved from the regression models alone.

Once the regression model is completed, it can also be used as a proxy model for the effect of SSI on stratospheric ozone. This offers a simple parameterisation of the effect of the SSI on stratospheric ozone which can be used to minimalize the computational burden of incorporating SSI variability in CCMs, and including non-linear wavelength dependences. A particular application of this parameterization is anticipated for mechanistic or sensitivity studies that involve long simulations since it can be used with simplified stratospheric chemistry schemes too (e.g. Taylor and Bourqui, 2005). We evaluate in this study the performance of the proposed regression models when used to represent the ozone perturbation due to SSI variability in our photochemical column model experiments. This provides a proof-of-concept for such a 
simple parameterisation, but further development in this direction is beyond the scope of this paper.

In a first step, we limit the study to the pre-defined solar maximum and minimum spectra from Lean (1997) and assume that the SSI follows a linear wavelength time variability between these two spectra. This allows comparison with previous studies in the context of constant solar maximum/minimum simulations. This first application of this simplified modelling framework presented in this paper provides a reference for further studies that will apply this framework to more advanced SSI variability reconstructions.

The next section describes the numerical model employed, the initial conditions, the simulations and the ensemble simulation approach. Section 3 presents the stratospheric chemical state for an average solar activity and discusses the results from the fixed solar minimum and maximum simulations for all relevant chemical families and partitioning ratios. Section 4 presents the results for odd oxygen from the ensemble simulations with daily random solar variability. It includes regression analyses with two and three predictors, the sensitivity to initial conditions, the independent evaluation of the regression models, and its sensitivity to the amplitude of solar variability. Finally, the conclusions are drawn in Sect. 5.

\section{Methodology}

\subsection{Photochemical model}

The chemistry column model used here is an adapted version of the stratospheric photochemical scheme developed for BASCOE (Errera et al., 2008; Viscardy et al., 2010) with updated JPL06/09 chemical rates (Sander et al., 2006, 2010). The scheme calculates the temporal evolution of 57 chemical species described by a system of 199 chemical reactions. The corresponding chemistry module is built by the Kinetic PreProcessor (Damian et al., 2002) and is integrated using a third-order Rosenbrock solver (Hairer and Wanner, 1996). For the purpose of this study, this chemical model was modified to include an on-line calculation of the photolysis rates. The scheme has 171 spectral wavelengths between $116.3-730 \mathrm{~nm}$ and includes 55 photodissociation processes that are solved using a two-stream radiative transfer method (Chabrillat and Fonteyn, 2003) and a simple parameterisation of the absorption of the solar Lyman-alpha line by molecular oxygen (Chabrillat and Kockarts, 1997). This interactive coupling allows photolysis rates to respond to vertically changing concentrations in absorbing species and removes the dependence on an a priori vertical profile of ozone. The coupled model is setup to calculate the photochemistry in each $1 \mathrm{~km}$ thick layer of a vertical column extending from 10 to $55 \mathrm{~km}$ altitude, with an external timestep of $6 \mathrm{~min}$. Daylight is assumed present only when the solar zenith angle is smaller than $96^{\circ}$. The absorbing gases are $\mathrm{O}_{3}, \mathrm{O}_{2}, \mathrm{NO}, \mathrm{NO}_{2}$, $\mathrm{CO}_{2}$, and air. Concentrations of chemically active absorbers
$\left(\mathrm{O}_{3}, \mathrm{NO}, \mathrm{NO}_{2}\right)$ are determined by the chemical solver. The chemically inert species and standard atmospheric temperatures and pressures are taken from MSIS (Hedin, 1991). The solar spectrum comes from Lean (1997) and includes maximum, minimum, and average solar irradiance at each wavelength interval. In order to account for absorption of solar irradiance above $55 \mathrm{~km}$ (above the upper boundary of the chemistry solver), an artificial standard upper atmosphere is added which is composed of 4 levels at 60, 80, 100, and $120 \mathrm{~km}$. Similarly, to account for tropospheric absorption of reflected solar irradiance at the surface, an artificial standard troposphere is added with 5 levels at $0,2,4,6$, and $8 \mathrm{~km}$. Extensive testing showed that these upper and lower levels were enough to represent photolysis rates between 10 and $55 \mathrm{~km}$ altitude without loss of accuracy.

\subsection{Numerical simulations}

All simulations start at midnight and occur in January at the Equator. We chose the Equator, where dynamical effects on ozone are smallest, to make our experiments more (although not entirely) comparable to CCMs. The initial concentrations and temperature are set to monthly and zonally averaged values taken from a 22-yr simulation with the Canadian Middle Atmosphere Model (Semeniuk et al., 2011) with greenhouse gases and halogen concentrations fixed to year 1979 (courtesy Kirill Semeniuk). Initial concentrations of longlived species are taken constant with altitude and are listed in Table 1. This simplification does not affect the results on the time scale studied here. The vertical profiles of the other chemical species, along with temperature are given in Fig. 1. The temporal evolution of all chemical species is calculated with the exception of only $\mathrm{N}_{2}$ and $\mathrm{O}_{2}$ that are kept constant with time.

As mentioned above, in order to concentrate on photochemical processes and avoid any distorsion of the results by external forcing effects, the model is used in a pure photochemistry mode and includes no external sources and sinks, nor transport or diffusion. It also keeps temperatures and pressures constant over time, so that the effects of the diurnal cycle are included through the solar irradiances only. Simulations are therefore performed in a transient mode, where chemical concentrations change according to their individual lifetimes. The changes in individual families (as well as the reservoirs) over time in a control simulation with average solar conditions are given in Table 2 as a percentage of the initial concentration. Long-lived species are not shown as they do not change significantly over the time period considered here. In order to keep the chemical system in a regime which is relevant to the stratosphere, all simulations in this study are thus limited to 10 days (maximum change smaller than $20 \%$ for the families and most of the reservoir species). In order to facilitate the discussion of the results, the focus will be placed on day 5 hereafter and variations of the results between days 3 to 9 will be discussed as required. This 

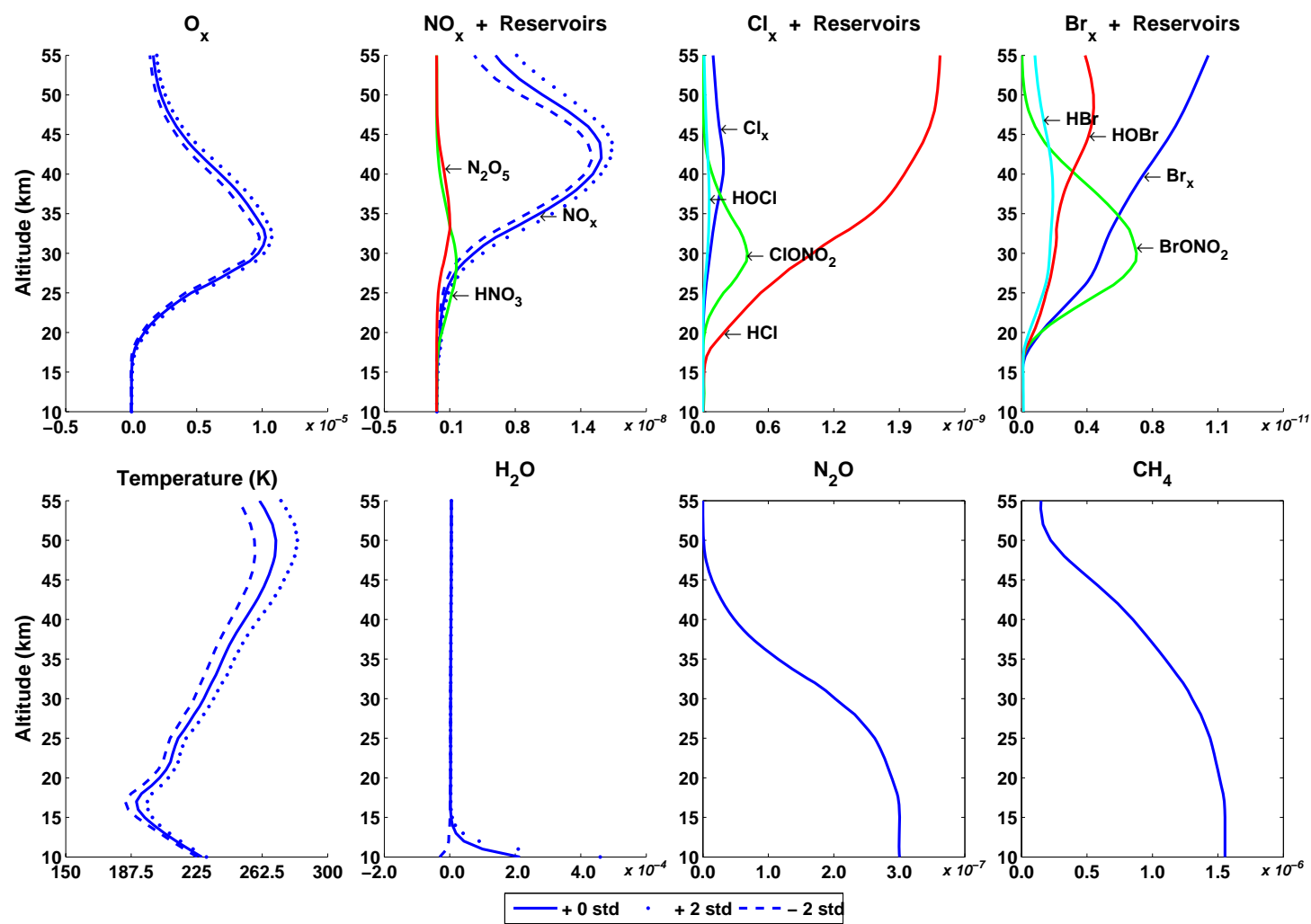

Fig. 1. Initial conditions used in the simulations for the interactive species (upper row) and the specified temperature and species (lower row) that vary with altitude. Initial conditions for specified species that have a constant mixing ratio with altitude are provided in Table 1 . Solid lines of different colours correspond to regular initial conditions, while the dashed and dotted lines represent the two-standard deviation perturbed initial conditions used in the simulations testing the sensitivity to the initial conditions (see text for more details). Chemical species are shown in units of volume mixing ratio, and the temperature in $\mathrm{K}$.

variation is of interest as it provides some additional insight into the sensitivity of the results to variations in chemical concentrations.

The first set of numerical experiments simulates the chemical response to various strengths of solar irradiance, with the solar irradiance kept constant through the simulations to: solar maximum, solar minimum, and solar average levels. The irradiance spectra represent the 11-yr maximum, minimum, and average solar irradiance for each wavelength interval (Lean, 1997).

The second set of numerical experiments investigates statistically the chemical response to daily solar variability and allows to build a simple auto-regressive model of the ozone perturbation. An ensemble of 200 transient simulations is performed, each forced by a different pseudo-random solar variability sequence. Solar irradiance is updated daily and held constant for $24 \mathrm{~h}$. Updates are at midnight to avoid a sudden change in the photolysis rates. Here again, the irradiance spectrum ranges between the solar minimum and solar maximum spectra of Lean (1997)'s 11-yr cycle following the linear formula in Eq. (1).

$$
\begin{gathered}
I^{i}(\lambda)=x^{i} \cdot I_{\max }(\lambda)+\left(1-x^{i}\right) \cdot I_{\min }(\lambda) \\
x^{i} \in[0,1], \quad i=1,10,
\end{gathered}
$$

where $I^{i}(\lambda)$ is the solar irradiance spectrum on day $i, I_{\max }(\lambda)$ is the maximum solar irradiance spectrum, and $I_{\min }(\lambda)$ the minimum spectrum. The pseudo-random number $x^{i}$ is updated every midnight from a uniform distribution within $[0,1]$. It is independent from $\lambda$, so that the entire spectrum is linearly varying between the solar minimum and maximum. To ensure good statistical independence between the 200 members, a sequence of 2000 successive pseudo-random numbers (without re-seed) is used and partitioned into the 200 members. Two auto-regressive models are discussed here for odd oxygen (i.e. ozone). The two-predictor model determines the diurnal average concentration for the current day, knowing the diurnal average concentration of the previous day and the solar irradiance perturbation of the current day. The three-predictor model is similar to the two-predictor model, but with the addition of the solar irradiance perturbation of the previous day as the third predictor. The details are discussed in Sect. 4. Note that as a first step, we chose here 
Table 1. Initial conditions for chemical species where mixing ratio is specified constant with altitude. Units are in mixing ratio. Initial mixing ratios that depend on altitude are given in Fig. 1.

\begin{tabular}{ll}
\hline Chemical Species & Initial mixing ratio \\
\hline $\mathrm{Br}_{2}$ & $0.1 \times 10^{-11}$ \\
$\mathrm{CCl}_{4}$ & $0.98 \times 10^{-10}$ \\
$\mathrm{CFC} 11$ & $0.236 \times 10^{-9}$ \\
$\mathrm{CFC} 12$ & $0.465 \times 10^{-9}$ \\
$\mathrm{CFC} 113$ & $0.679 \times 10^{-10}$ \\
$\mathrm{CFC} 114$ & $0.153 \times 10^{-10}$ \\
$\mathrm{CFC} 115$ & $0.37 \times 10^{-11}$ \\
$\mathrm{CH}_{3}$ & $1.0 \times 10^{-20}$ \\
$\mathrm{CH}_{3} \mathrm{Br}$ & $0.837 \times 10^{-11}$ \\
$\mathrm{CH}_{3} \mathrm{CCl} l_{3}$ & $0.59 \times 10^{-10}$ \\
$\mathrm{CH}_{3} \mathrm{Cl}$ & $0.469 \times 10^{-9}$ \\
$\mathrm{CH}_{3} \mathrm{O}$ & $1.0 \times 10^{-20}$ \\
$\mathrm{CH}_{3} \mathrm{O}_{2}$ & $1.0 \times 10^{-20}$ \\
$\mathrm{CHBr}_{3}$ & $0.37 \times 10^{-12}$ \\
$\mathrm{Cl}_{2}$ & $0.2 \times 10^{-13}$ \\
$\mathrm{ClNO}_{2}$ & $1.0 \times 10^{-20}$ \\
$\mathrm{ClOO}_{\mathrm{H}_{2}}$ & $0.2 \times 10^{-9}$ \\
$\mathrm{HA} 1211$ & $0.5 \times 10^{-6}$ \\
$\mathrm{HA} 1301$ & $0.22 \times 10^{-11}$ \\
$\mathrm{HCFC} 22$ & $0.26 \times 10^{-11}$ \\
$\mathrm{HCO}$ & $0.92 \times 10^{-10}$ \\
$\mathrm{HF}$ & $1.0 \times 10^{-20}$ \\
\hline & $1.0 \times 10^{-20}$ \\
\hline &
\end{tabular}

to focus on Equatorial January conditions, and the study can be later generalised by allowing the regression coefficients to vary with latitude and month.

Since chemical concentrations and temperatures vary significantly over longitudes and within seasons, it is useful to test the sensitivity of the latter results to the initial conditions. To do this, a third set of numerical experiments is performed, where temperature and initial conditions of relevant species are perturbed, one variable at a time. The same approach is employed as before, but with ensembles of 100 simulations. The perturbations represent the intra-month and zonal variability, averaged over the $22 \mathrm{yr}$ of the CMAM simulation of the two-standard deviations of three-daily values of the variable taken at the given altitude and latitude. Note that these standard deviations are used here merely as an estimate of the possible range of variation of the variables. The sensitivity analysis is performed for odd hydrogen $\left(\mathrm{HO}_{\mathrm{x}}=\{\mathrm{H}\right.$, $\left.\mathrm{OH}, \mathrm{HO}_{2}\right\}$ ) by perturbing $\mathrm{H}_{2} \mathrm{O}$, odd nitrogen $\mathrm{NO}_{\mathrm{x}}=\{\mathrm{NO}$, $\left.\mathrm{NO}_{2}, \mathrm{NO}_{3}\right\}$, odd oxygen $\mathrm{O}_{\mathrm{x}}=\left\{\mathrm{O}^{3} \mathrm{P}, \mathrm{O}^{1} \mathrm{D}, \mathrm{O}_{3}\right\}$, and temperature. These chemical species are chosen as they make the dominant contribution to ozone photochemistry. $\mathrm{H}_{2} \mathrm{O}$ is the main source of $\mathrm{HO}_{\mathrm{x}}$, which dominates ozone destruction in the lower and upper stratosphere. $\mathrm{NO}_{\mathrm{x}}$ dominates ozone destruction in the middle stratosphere, and $\mathrm{O}_{\mathrm{x}}$ is chosen to see if
Table 2. Maximum percent change from initial condition throughout the stratosphere, after 5, 10, 15, and 25 days of simulation for the relevant chemical species, with corresponding altitude.

\begin{tabular}{lcrrrr}
\hline $\begin{array}{c}\text { Chemical } \\
\text { species }\end{array}$ & $\begin{array}{c}\text { Altitude of } \\
\text { max change }(\mathrm{km})\end{array}$ & \multicolumn{5}{c}{ Percent } & 5 days & 10 days & 15 days & 25 days \\
\hline $\mathrm{Br}_{\mathrm{X}}$ & 25 & 2.9 & 5.1 & 6.7 & 9.3 \\
$\mathrm{Cl}_{\mathrm{x}}$ & 45 & 1.1 & 3.1 & 5.0 & 8.9 \\
$\mathrm{HO}_{\mathrm{x}}$ & 35 & 0.04 & -0.18 & -0.46 & -1.0 \\
$\mathrm{NO}_{\mathrm{x}}$ & 55 & -1.5 & -3.9 & -6.3 & -10.6 \\
$\mathrm{O}_{\mathrm{x}}$ & 25 & 1.4 & 3.7 & 5.8 & 9.6 \\
$\mathrm{BrONO}$ & & 0.37 & 1.0 & 1.6 & 2.8 \\
$\mathrm{ClONO}$ & 35 & 2.4 & 7.1 & 11.7 & 20.2 \\
$\mathrm{HBr}$ & 25 & -3.5 & -4.5 & -5.3 & -6.5 \\
$\mathrm{HCl}$ & 30 & 0.52 & 1.3 & 2.2 & 3.7 \\
$\mathrm{HNO}$ & 35 & 7.2 & 12.7 & 15.7 & 20.5 \\
$\mathrm{HOBr}$ & 25 & 2.8 & 5.4 & 7.4 & 10.7 \\
$\mathrm{HOCl}$ & 25 & 14.8 & 28.3 & 36.0 & 46.8 \\
$\mathrm{~N}_{2} \mathrm{O}_{5}$ & 25 & -1.7 & 0.13 & 2.7 & 7.8 \\
\hline
\end{tabular}

different concentrations of ozone result in different responses to solar variability. Finally, temperature is chosen because of the temperature dependence of ozone destroying reactions.

Then, a fourth set of experiments is made to test the performance of the auto-regressive model at representing the ozone perturbation due to solar variability. For this purpose, five additional ensembles of 200 simulations are designed as follows using a new pseudo-random solar variability sequence adjacent to the first sequence. The same pseudo-random sequence is used in all these new ensembles, so that they can be inter-compared on a member-by-member basis.

1. Control ensemble with daily random solar variability performed as before using the photochemical model;

2. two-predictor auto-regressive model used off-line on top of a solar average simulation with the photochemical model;

3. two-predictor auto-regressive model used on-line with the photochemical model representing the solar average conditions;

4. same as 2, but with the three-predictor auto-regressive model;

5. same as 3, but with the three-predictor auto-regressive model.

Note that in the two on-line experiments 3 and 5 above, the auto-regressive model is curtailed by its previous day's concentration component since this memory is carried over by the photochemical model itself. More details and the results of these five simulations are presented in Sect. 4.3.

Finally, a last set of solar maximum/solar minimum experiments is performed with the photochemical model, the 2 and the 3-predictor models, using solar maximum and minimum spectra such that their difference centered around the solar average spectrum is magnified by a factor between 0.1 to 3.0. This magnifying factor is applied either uniformly 
to the whole spectrum or to the range 200 to $400 \mathrm{~nm}$ (see Sect. 4.4).

\section{Results from simulations with constant solar irradiance}

In this section results of constant solar irradiance simulations are presented for the following chemical families and partitioning ratios: $\mathrm{O}_{\mathrm{x}}, \mathrm{NO}_{\mathrm{x}}, \mathrm{HO}_{\mathrm{x}}, \mathrm{Cl}_{\mathrm{x}}=\{\mathrm{Cl}, \mathrm{ClO}\}, \mathrm{Br}_{\mathrm{x}}=\{\mathrm{Br}$, $\mathrm{BrO}\}, \frac{\mathrm{O}}{\mathrm{O}_{\mathrm{x}}}, \frac{\mathrm{NO}}{\mathrm{NO}_{\mathrm{x}}}, \frac{\mathrm{OH}}{\mathrm{HO}}, \frac{\mathrm{Cl}}{\mathrm{Cl}_{\mathrm{x}}}$, and $\frac{\mathrm{Br}}{\mathrm{Br}_{\mathrm{x}}}$. To place in context the response of chemical families to solar variability, it is useful to first briefly map the chemical state for average solar irradiance (SI) conditions. This is represented in Fig. 2 by the diurnal cycle of day 5 of the simulation using average SI. The variation in the pattern of this diurnal cycle through the ten days of the simulation is minor and its diurnal average change is provided in Table 2. Note that these diurnal cycles are consistent with Brasseur et al. (1990) and Dessler (2000), for instance.

Figure 3 shows the diurnal cycle difference between the solar maximum and the solar minimum experiments, taken on day 5 . Note that in both the solar maximum and solar minimum experiment, the entire chemical system may slowly adjust to the solar perturbation, and therefore a slow temporal drift may occur in addition to the diurnal response. However, above $35 \mathrm{~km}$, where the photochemistry is in steady state, and therefore the $\mathrm{O}_{\mathrm{x}}$ response should stay constant in the absence of such an adjustment, a change in the $\mathrm{O}_{\mathrm{x}}$ response smaller than $10 \%$ was found from day 5 to day 10 (not shown). Below this altitude, the ozone response changes by $60 \%$ over this period between 15 and $25 \mathrm{~km}$ altitude due to the ozone chemistry becoming slower at low altitudes, and not because of an adjustment of the overall chemical system. Hence, it is sound to focus on the day 5 of the simulation, keeping in mind that the steady state response is only achieved above $35 \mathrm{~km}$.

$\mathrm{O}_{\mathrm{x}}$ : Fig. 3 shows that the minimum-to-maximum difference is positive for both $\mathrm{O}_{\mathrm{x}}$ and $\frac{\mathrm{O}}{\mathrm{O}_{\mathrm{x}}}$. The peak difference for $\mathrm{O}_{\mathrm{x}}$ is approximately $0.18 \mathrm{ppmv}(\sim 3 \%)$ at $37 \mathrm{~km}$, just above the ozone peak altitude, and remains throughout the diurnal cycle. Note that the relative change peaks slightly higher $(3.2 \%$ at $42 \mathrm{~km})$ due to the decreasing $\mathrm{O}_{\mathrm{x}}$ concentration with altitude (Fig. 9, top panel). These results are within the range of the minimum-to-maximum differences calculated from the observations by Soukharev and Hood (2006) and Fioletov (2009), and is in agreement with the largest minimum-to-maximum differences calculated from simulations by 1-D models (e.g. Rozanov et al., 2002), $2-$ D models (e.g. Haigh, 1994) and CCMs (e.g. Shindell et al., 1999; Tourpali et al., 2003; Egorova et al., 2004; Rozanov et al., 2004). The difference for $\frac{\mathrm{O}}{\mathrm{O}_{x}}$ is only seen during the day above $48 \mathrm{~km}$, and the peak difference is a change in the partitioning ratio of approximately $1.6 \times 10^{-3}(\sim 1 \%)$ near the top of the model $(55 \mathrm{~km})$. The peak change in $\frac{\mathrm{O}}{\mathrm{O}_{\mathrm{x}}}$ oc- curs at the top of the model because this is where the UV irradiance is strongest, allowing for an enhanced photolysis of $\mathrm{O}_{3}$. The increased $\mathrm{O}_{2}$ photolysis is the reason for the increase in $\mathrm{O}_{\mathrm{x}}$ during solar maximum conditions. The peak difference occurs a few kilometers above the maximum $\mathrm{O}_{\mathrm{x}}$ mixing ratio due to a change in the optical depth and in the $\mathrm{O}_{\mathrm{x}}$ loss processes. An increase in $\mathrm{HO}_{\mathrm{x}}$ above $40 \mathrm{~km}$ during solar maximum conditions (see below) results in an increased destruction of $\mathrm{O}_{x}$, thus limiting the response of $\mathrm{O}_{x}$ to SI above $40 \mathrm{~km}$. Similar results were obtained for the upper stratosphere and mesosphere in simulations by 2-D models (e.g. Brasseur, 1993; Khosravi et al., 2002) and CCMs (e.g. Egorova et al., 2005), and in observations by Zhou et al. (1997).

$\mathrm{HO}_{\mathrm{x}}$ : as expected, Fig. 3 shows that the minimum-tomaximum difference occurs mostly during the day for $\mathrm{HO}_{\mathrm{x}}$ and $\frac{\mathrm{OH}}{\mathrm{HO}_{\mathrm{x}}}$. The difference for $\mathrm{HO}_{\mathrm{x}}$ is positive and occurs above $40 \mathrm{~km}$, reaching a peak value of $0.03 \mathrm{ppbv}(\sim 2.5 \%)$ at the top of the model. A similar increase in $\mathrm{HO}_{\mathrm{x}}$ during solar maximum conditions is found in the CCM simulations of Egorova et al. (2005). For $\frac{\mathrm{OH}}{\mathrm{HO}_{\mathrm{x}}}$, the difference is negative and is found in the middle stratosphere, with a peak difference of approximately $-3 \times 10^{-3}(\sim-1 \%)$ at $38 \mathrm{~km}$. The difference found at night above $50 \mathrm{~km}$ should be ignored as there is no $\mathrm{HO}_{\mathrm{x}}$ present here, and the difference is simply a result of a near-zero denominator. The peak increase in $\mathrm{HO}_{\mathrm{x}}$ is the result of an increase in the oxidation of water vapour and methane, and is found where the SI is strongest. The decrease in $\frac{\mathrm{OH}}{\mathrm{HO}_{\mathrm{x}}}$ in the middle stratosphere is a result of the increase of $\mathrm{O}_{\mathrm{x}}$ at these altitudes, as well as the decrease in NO. In the middle stratosphere, the conversion of $\mathrm{OH}$ to $\mathrm{HO}_{2}$ (via $\mathrm{O}_{3}$ ) and the conversion of $\mathrm{HO}_{2}$ to $\mathrm{OH}$ (via NO) dominate the $\mathrm{HO}_{\mathrm{x}}$ cycle (Dessler, 2000). Thus an increase in $\mathrm{O}_{\mathrm{x}}$ leads to an enhanced conversion of $\mathrm{OH}$ to $\mathrm{HO}_{2}$, and a decrease in NO leads to a diminished conversion of $\mathrm{HO}_{2}$ back into $\mathrm{OH}$. The small decrease seen at the top of the model is due to the increase in $\mathrm{O}$ atoms at the top of the model, resulting in an increased conversion of $\mathrm{OH}$ to $\mathrm{HO}_{2}$ via $\mathrm{O}$. In the CCM simulations by Egorova et al. (2005), an increase in $\mathrm{HO}_{2}$ is found between 25 to $55 \mathrm{~km}$, in agreement with the decrease in $\frac{\mathrm{OH}}{\mathrm{HO}_{\mathrm{x}}}$ found here.

$\mathrm{NO}_{\mathrm{x}}$ : in Fig. 3 it can be seen that there is both a positive and negative difference in the minimum-to-maximum $\mathrm{NO}_{\mathrm{x}}$. The negative difference peaks at a value of $-0.1 \mathrm{ppbv}$ $(\sim-1 \%)$ late in the night at around $40 \mathrm{~km}$. There is also a slightly smaller negative difference above $40 \mathrm{~km}$ that remains throughout the diurnal cycle and peaks above $50 \mathrm{~km}$. The positive difference in $\mathrm{NO}_{\mathrm{x}}$ is seen during the day and has a peak value of approximately $0.03 \mathrm{ppbv}(\sim 0.5 \%)$ at about $32 \mathrm{~km}$. The minimum-to-maximum difference for $\frac{\mathrm{NO}}{\mathrm{NO}_{\mathrm{x}}}$ is negative and is mainly found in the middle stratosphere during the day, with a peak difference of $-4 \times 10^{-3}(\sim-1 \%)$ at around $37 \mathrm{~km}$. During the night, the decrease in $\mathrm{NO}_{\mathrm{x}}$ at around $40 \mathrm{~km}$ is a result of the increase in $\mathrm{O}_{\mathrm{x}}$ at this altitude during solar maximum. An increase in $\mathrm{O}_{\mathrm{x}}$ results in an 

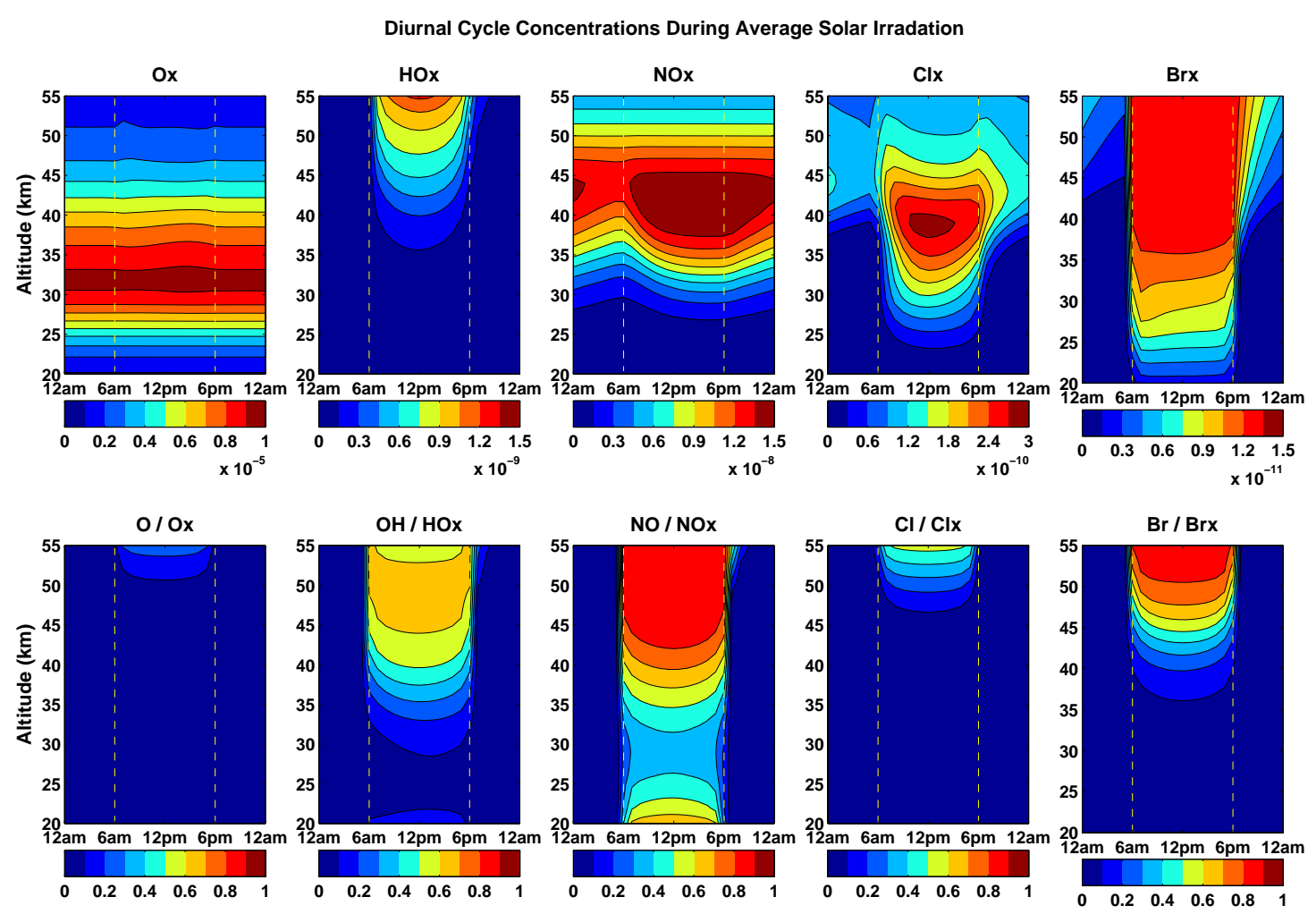

Fig. 2. Diurnal cycle of the relevant chemical families and their partitioning ratio on day 5 of the solar average simulation. Chemical families are shown in units of volume mixing ratio. Vertical yellow dashed lines show the sunrise and sunset times, 06:00 a.m. and 06:00 p.m., respectively.

increased conversion of $\mathrm{NO}_{2}$ to $\mathrm{NO}_{3}\left(\mathrm{via} \mathrm{O}_{3}\right)$, which then results in an increase in the conversion of $\mathrm{NO}_{\mathrm{x}}$ to its reservoir $\mathrm{N}_{2} \mathrm{O}_{5}$ (through the combination of $\mathrm{NO}_{2}$ and $\mathrm{NO}_{3}$ ). The negative minimum-to-maximum difference above $40 \mathrm{~km}$ during the day is due to an increase in $\mathrm{N}$ atoms (via an increased photolysis of NO), resulting in an enhanced conversion of $\mathrm{NO}$ to $\mathrm{N}_{2}$ (via $\mathrm{N}$ ), thus causing a loss in $\mathrm{NO}_{\mathrm{x}}$. The increase of $\mathrm{NO}_{\mathrm{x}}$ seen during the day is due to an increase in the conversion of the $\mathrm{NO}_{\mathrm{x}}$ reservoirs (specifically $\mathrm{HNO}_{3}$ ) back into $\mathrm{NO}_{\mathrm{x}}$ (specifically $\mathrm{NO}_{2}$ ) due to enhanced photolysis. The strongest response is located at around $32 \mathrm{~km}$. This is due to the combination of $\mathrm{HNO}_{3}$ decreasing at higher altitudes and the photolysis of $\mathrm{HNO}_{3}$ slowing down at lower altitudes. The decrease found in the middle stratosphere is due to the increase in $\mathrm{O}_{\mathrm{x}}$ at these altitudes, which results in an increased conversion of $\mathrm{NO}$ to $\mathrm{NO}_{2}\left(\right.$ via $\left.\mathrm{O}_{3}\right)$. Again, in the simulations by Egorova et al. (2005), an increase in $\mathrm{NO}_{2}$ is found at these altitudes, and is thus in agreement with the decrease in $\frac{\mathrm{NO}}{\mathrm{NO}_{\mathrm{x}}}$ found here.

$\mathrm{Cl}_{\mathrm{x}}$ : Fig. 3 shows that the minimum-to-maximum difference is positive for both $\mathrm{Cl}_{\mathrm{x}}$ and $\frac{\mathrm{Cl}}{\mathrm{Cl}_{\mathrm{x}}}$. The increase in $\mathrm{Cl}_{\mathrm{X}}$ occurs during the day with a peak value of 3 pptv $(\sim 1 \%)$ around $40 \mathrm{~km}$ and slowly decays through the night. The difference for $\frac{\mathrm{Cl}}{\mathrm{Cl}_{\mathrm{x}}}$ is seen only during the day above $47 \mathrm{~km}$, with a peak value of $2.4 \times 10^{-3}(\sim 0.4 \%)$ at the top of the model. The increase in $\mathrm{Cl}_{\mathrm{x}}$ in the middle stratosphere is due to the enhanced conversion of $\mathrm{Cl}_{\mathrm{X}}$ reservoirs (mainly $\mathrm{ClONO}_{2}$ ) back into $\mathrm{Cl}_{\mathrm{x}}$ due to enhanced photolysis during solar maximum conditions. Also, since photolysis is the primary decomposition channel for CFCs (Dessler, 2000) and the added $\mathrm{Cl}$ goes mainly into $\mathrm{ClONO}_{2}$ and $\mathrm{HCl}$, the increase in reservoirs results in a further conversion back into $\mathrm{Cl}_{\mathrm{X}}$ (via photolysis) during the day. The peak change in $\frac{\mathrm{Cl}}{\mathrm{Cl}_{\mathrm{x}}}$ at the top of the model $(55 \mathrm{~km})$ is due to increased $\frac{\mathrm{O}}{\mathrm{O}_{\mathrm{x}}}$, resulting in an enhanced conversion of $\mathrm{ClO}$ to $\mathrm{Cl}$ (via O). Simulations by Egorova et al. (2005) found a decrease in $\mathrm{ClO}$ between 45 to $55 \mathrm{~km}$, and are thus in agreement with the increase in $\frac{\mathrm{Cl}}{\mathrm{Cl}_{\mathrm{x}}}$ found here.

$\mathrm{Br}_{\mathrm{x}}$ : Fig. 3 shows a negative difference in $\mathrm{Br}_{\mathrm{x}}$ occuring at night essentially above $45 \mathrm{~km}$, reaching a peak value of -0.08 pptv $(\sim-0.3 \%)$. For $\frac{\mathrm{Br}}{\mathrm{Br}_{\mathrm{x}}}$, the difference is negative and is found during the day, with a peak value of $-5 \times 10^{-3}$ $(\sim-2.5 \%)$ around $42 \mathrm{~km}$. Above $45 \mathrm{~km}$, the large negative change in $\mathrm{Br}_{\mathrm{x}}$ during the night is due to the decrease in $\frac{\mathrm{OH}}{\mathrm{HO}_{\mathrm{x}}}$ (seen previously), resulting in an increased conversion of $\mathrm{BrO}$ to its reservoir $\mathrm{HOBr}$ (via $\mathrm{HO}_{2}$ ), and thus a decrease in $\mathrm{Br}_{\mathrm{x}}$. Similarly to $\frac{\mathrm{NO}}{\mathrm{NO}_{\mathrm{x}}}$, the decrease in $\frac{\mathrm{Br}}{\mathrm{Br}_{\mathrm{x}}}$ in the middle 

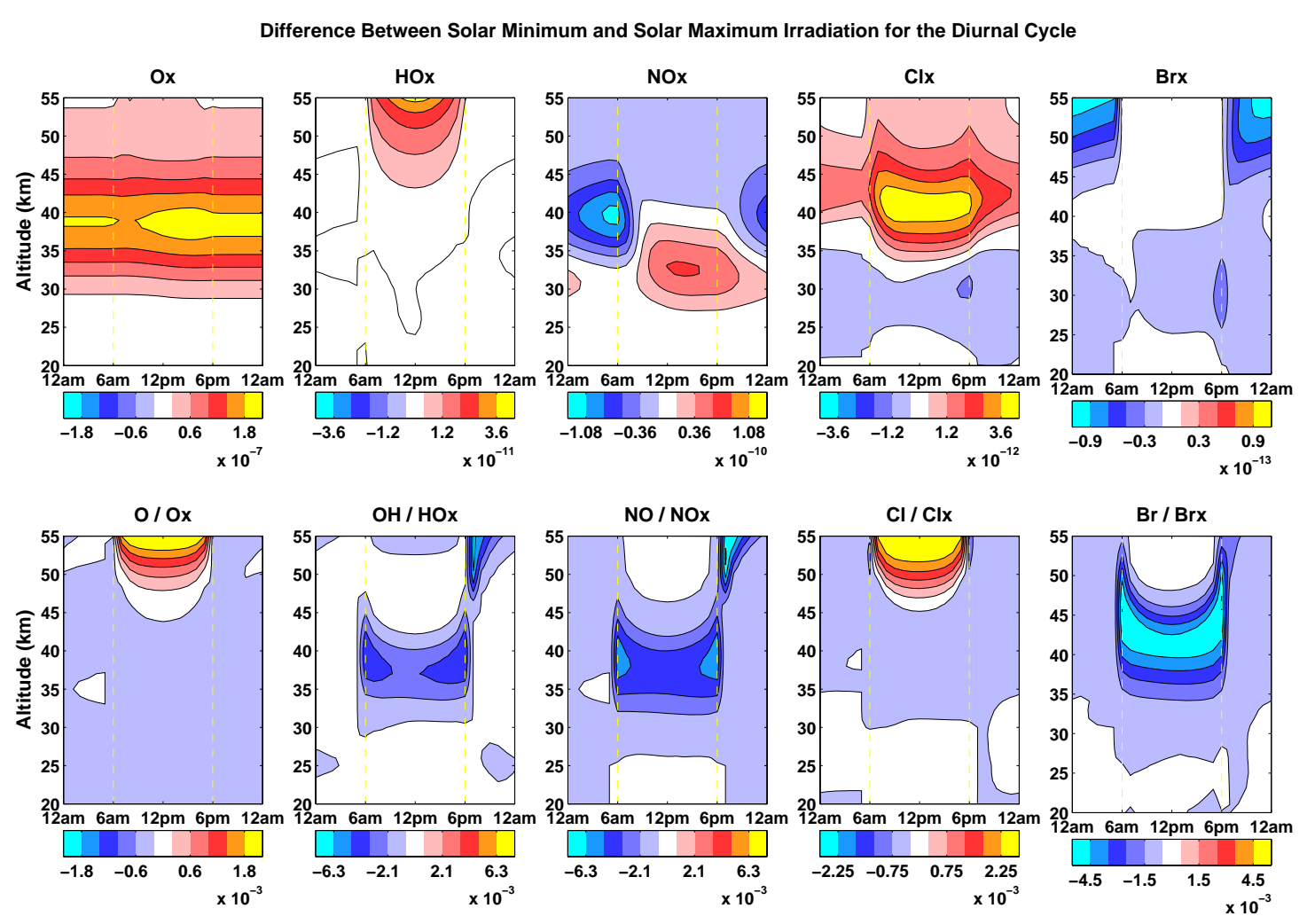

Fig. 3. Diurnal cycle of the chemical differences between the constant solar maximum and minimum simulations on day 5 for the relevant chemical families and their partitioning ratios. Differences in chemical families are shown in units of volume mixing ratio, and in arbitrary units for partitioning ratios. Vertical yellow dashed lines show the sunrise and sunset times, 06:00 a.m. and 06:00 p.m., respectively.

stratospheric daytime is due to the increase in $\mathrm{O}_{\mathrm{x}}$, resulting in an enhanced conversion of $\mathrm{Br}$ to $\mathrm{BrO}\left(\mathrm{via}_{3}\right.$ ).

\section{Results from ensemble simulations with daily random solar variability}

In this section, the effect of short-term solar variability on $\mathrm{O}_{\mathrm{x}}$ is approached from a statistical perspective using multiple linear regressions on ensembles of simulations. The goal is to develop the simplest statistical model which captures the odd oxygen response in a complete manner. This statistical model, through its coefficients, characterises the ozone response to the type of SSI variability considered here and can be used to predict the odd oxygen response to an arbitrary time series of SSI (e.g. a 27-day cycle). This provides a simple framework for inter-comparing different SSI variability reconstructions/models with respect to their effect on the stratosphere. It also gives an approach for developing a simple parameterisation of the odd oxygen response to SSI variability.

The regression model's dependent variable $(y)$ is taken as the daily $(24 \mathrm{~h})$ average concentration of each ensemble member for days 3-9. Days 1 and 2 are left out to allow for a spin-up in the simulations. In order to verify that the re- gression coefficients do not vary significantly over the course of the simulations, separate regressions are performed every day. The ensemble size of 200 members was found to be large enough so that results are not significantly sensitive to it. Two auto-regressive models are tested: a 2-predictor and a 3 -predictor model. In the 2-predictor model, the independent variables are taken as the previous day's daily average concentration $\left(x_{1}\right)$, and the current day's SI $\left(x_{2}\right)$. The dependence on the previous day's daily average concentration is referred to as the memory and the current day's SI as the SI for simplicity. In the 3-predictor model, the additional independent variable is the previous day's SI $\left(x_{3}\right)$. The previous day's SI is added in an attempt to include the effects of SI on the chemistry that are too slow to be captured by the current day's SI regression term. Such effects include for instance changes in other species that indirectly affect $\mathrm{O}_{\mathrm{x}}$. The multiple linear regression models can be written in the standardised form as, respectively:

$$
\begin{aligned}
\frac{y^{i}-\bar{y}^{i}}{\sigma_{y}^{i}} & =\beta^{i} \frac{x_{1}^{i}-\bar{x}_{1}^{i}}{\sigma_{x_{1}}^{i}}+\gamma^{i} \frac{x_{2}^{i}-\bar{x}_{2}^{i}}{\sigma_{x_{2}}^{i}}+r^{i} i=3,9 \\
\frac{y^{i}-\bar{y}^{i}}{\sigma_{y}^{i}} & =\beta^{i} \frac{x_{1}^{i}-\bar{x}_{1}^{i}}{\sigma_{x_{1}}^{i}}+\gamma^{i} \frac{x_{2}^{i}-\bar{x}_{2}^{i}}{\sigma_{x_{2}}^{i}}+\delta^{i} \frac{x_{3}^{i}-\bar{x}_{3}^{i}}{\sigma_{x_{3}}^{i}}+r^{i} \quad i=3,9,(3)
\end{aligned}
$$


$y^{i}=x_{1}^{i+1}$.

The superscript $i$ is the day, overbars ${ }^{-}$represent the ensemble averages and $\sigma$. the ensemble standard deviation of the corresponding variable, and $r$ is the residual. The regression coefficient $\beta$ represents the standardised memory effect, $\gamma$ the standardised SI effect and $\delta$ the standardised previous day's SI effect. By definition, these standardised regression coefficients are always between -1 and +1 and show the relative contributions of predictors at every altitude, without regard to the actual ozone response. The intercept coefficient $\alpha$ is zero in these standardised forms. Note that although the two regression models have distinct values of the coefficients $\beta$ and $\gamma$, we use the same notation for simplicity. The ensemble averages can be expected to represent solar average conditions under the hypothesis of large ensembles and a linear ozone response. The difference between the ensemble average $\bar{y}$ (or equivalently $\bar{x}_{1}$ ) and the solar average simulation is smaller than $0.1 \%$ of the solar average $\mathrm{O}_{\mathrm{x}}$ everywhere (not shown) and therefore these two quantities can be assumed equal. The following form will also be used for the regression models, which measures the centered, non-normalised contribution of the different predictors to the ozone response:

$$
\begin{aligned}
y^{i}= & \alpha^{\prime i}+\beta^{\prime i}\left(x_{1}^{i}-\bar{x}_{1}^{i}\right)+\gamma^{\prime i}\left(x_{2}^{i}-\bar{x}_{2}^{i}\right)+r^{\prime i} \quad i=3,9 \\
y^{i}= & \alpha^{\prime i}+\beta^{\prime i}\left(x_{1}^{i}-\bar{x}_{1}^{i}\right)+\gamma^{\prime i}\left(x_{2}^{i}-\bar{x}_{2}^{i}\right)+\delta^{\prime i}\left(x_{3}^{i}-\bar{x}_{3}^{i}\right)+r^{\prime i} \\
& i=3,9
\end{aligned}
$$

where by definition, the intercept $\alpha^{\prime}$ equals $\bar{y}$, i.e. to a good approximation the ozone concentration in average solar conditions, and the regression coefficients $\beta^{\prime}, \gamma^{\prime}$ and $\delta^{\prime}$ are related to the standardised ones by:

$\beta^{\prime i}=\beta^{i} \frac{\sigma_{y}^{i}}{\sigma_{x_{1}}^{i}}, \gamma^{\prime i}=\gamma^{i} \frac{\sigma_{y}^{i}}{\sigma_{x_{2}}^{i}}, \delta^{\prime i}=\delta^{i} \frac{\sigma_{y}^{i}}{\sigma_{x_{3}}^{i}}$, and $r^{\prime}=r \sigma_{y}$.

These regression coefficients provide the actual contribution to $y-\bar{y}$ of a positive perturbation by one standard deviation in the previous day's ozone concentration, the current day's SI and the previous day's SI, respectively. The two predictors $x_{1}$ and $x_{2}$ are independent. As a result, in the 2predictor model, the corresponding coefficients $\beta^{\prime}$ and $\gamma^{\prime}$ can be interpreted independently from each other, as the ozone response to a positive perturbation by one standard deviation in the previous day's ozone concentration and the current day's SI, respectively. By contrast, since the ozone concentration on the previous day depends on the previous day's SI, the third predictor $x_{3}$ is expected to have some collinearity with $x_{1}$. The degree of this collinearity is indeed measured by the 2-predictor coefficients $\beta$ and $\gamma$. If a perfect collinearity exists somewhere in the column between $x_{1}$ and $x_{3}$, we will have $\beta=0$ and $\gamma=1$. Such a situation would make the third predictor useless and the corresponding regression coefficients $\beta$ and $\delta$ in the 3-predictor model ill-defined with only their sum being well-constrained. As will be seen below, the 2-predictor model's $\beta$ never goes to zero. This means that the third predictor brings additional information at all altitudes, and that the coefficients $\beta$ and $\delta$ in the 3-predictor model can be expected to be well-constrained everywhere. A more formal confirmation of this was made by calculating the variance inflation factor (VIF) for the third predictor, defined by (Wilks, 2006):

$\operatorname{VIF}\left(x_{3}\right)=\frac{1}{1-R_{x_{3}}^{2}}$,

where $R_{x_{3}}^{2}$ is the coefficient of determination for the regression of the previous day's SI on the memory. Usually, VIF $>10$ is considered the cut-off threshold where multicollinearity is too large in a regression and will lead to illdefined coefficients. In our case, VIF is smaller than 10 at all altitudes where the previous day's SI has a significant effect, and thus multicollinearity is not making the regression illdefined. However, it is important to note that the collinearity between $x_{1}$ and $x_{3}$ makes the intepretation of the corresponding regression coefficients less straightforward. The two regression coefficients must be interpreted together to the extent of the correlation between the two predictors.

The error of a regressive model in representing the ozone response can be simply measured by the coefficient of determination $R^{2}$ (Wilks, 2006). However, the comparison of this coefficient between the two models may lead to a bias favouring the 3-predictor one, simply due to the addition of an explanatory term and its effect in decreasing the number of degrees of freedom in the regression estimation. To take this effect into account, we use the coefficient of determination adjusted for the number of predictor variables $\left(\bar{R}^{2}\right)$ (Wilks, 2006):

$\bar{R}^{2}=1-\left(1-R^{2}\right) \frac{n-1}{n-p-1}$,

where $n$ is the sample size and $p$ is the total number of predictor variables in the regression. By definition, $\bar{R}^{2}$ is always smaller than $R^{2}$. As the number of predictors increases, the adjusted coefficient $\bar{R}^{2}$ increases only if the new predictor adds significantly to the fit, and may decrease if it does not.

\subsection{Regression coefficients}

Figures 4 and 5 show both the standardised and nonnormalised regression coefficients determined from the multiple linear regression using 2- and 3-predictors, respectively. Each day is represented with a different line colour. In each plot, altitudes at which the standard deviation (amongst the ensemble) in the observed variable $y$ was smaller than $5 \%$ of the maximum standard deviation in the column are hatched out, and are considered insignificant response to solar variability. Note that the regression analysis was performed on all species discussed in Sect. 3, and all species could be reasonably well regressed with the 3-predictor model, with an 

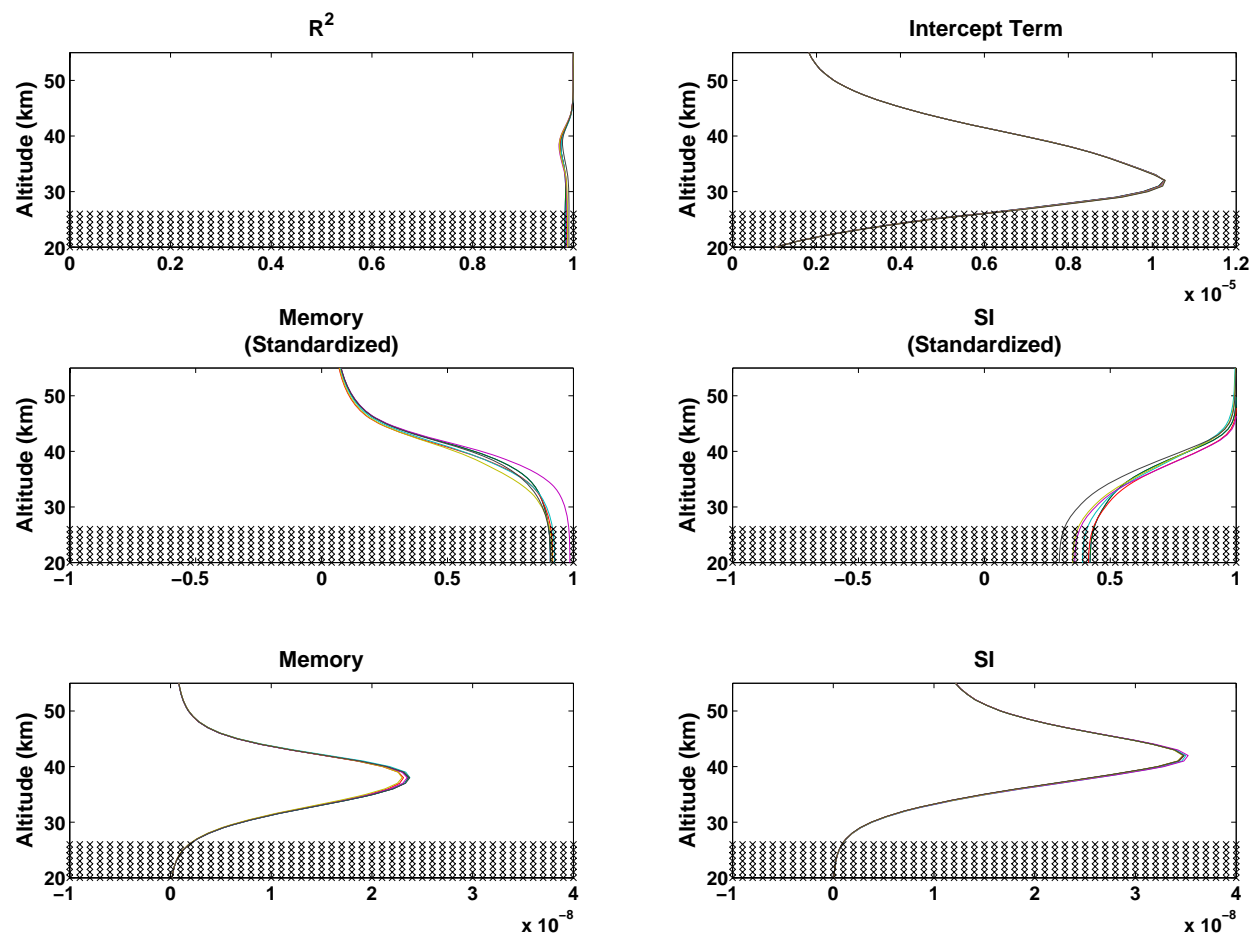

$$
\text { Day } 3-\text { Day } 4-\text { Day } 5-\text { Day } 6-\text { Day } 7 — \text { Day } 8-\text { Day } 9
$$

Fig. 4. Regression coefficients for the 2-predictor autoregressive model for simulation days 3 to 9 (different colours). Top row: adjusted coefficient of determination $\bar{R}^{2}$ (left) and intercept term $\alpha^{\prime}=\bar{y}$ (right). Middle row: standardised memory term $\beta$ (left) and standardised solar irradiance term $\gamma$ (right). Lower row: non-normalised memory term $\beta^{\prime}$ (left) and non-normalised solar irradiance term $\gamma^{\prime}$ (right). Regions where the standard deviation (amongst the ensemble) in the observed variable $y$ was smaller than $5 \%$ of the maximum standard deviation in the column are hatched out.

adjusted coefficient of determination larger than 0.8 at all altitudes (not shown).

Figure 4 shows that the adjusted coefficient of determination for the 2-predictor model is larger than 0.97 throughout the column, demonstrating that the 2-predictor linear model provides a reasonable representation of the response. Consistently with Fig. 2, the intercept term (from the nonnormalised regression) shows that the peak daily average mixing ratio of $\mathrm{O}_{\mathrm{x}}$ in solar average conditions occurs around $32 \mathrm{~km}(\sim 9 \mathrm{ppmv})$. The standardised regression coefficients shows that the current day's SI is dominant in the upper stratosphere (above $40 \mathrm{~km}$ ) where the UV irradiance is intense and chemical life-times are short, whereas the memory is dominant in the mid to lower stratosphere where chemical lifetimes of $\mathrm{O}_{\mathrm{x}}$ are longer. Nevertheless, both these 2predictors appear to have a significant effect at all altitudes considered here. The non-normalised regression coefficients confirm that the current day's SI dominates in the upper statosphere with a peak around $42 \mathrm{~km}$, and the memory in the mid stratosphere with a peak around $38 \mathrm{~km}$. Both memory and SI coefficients decrease to zero in the lower stratosphere as the chemistry becomes very slow and the overall response $\sigma_{y}$ converges to zero. As expected, the two regression coeffi- cients are positive throughout the stratosphere, meaning that increases in previous day's concentration or in current day's SI, both increase the current day's $\mathrm{O}_{\mathrm{x}}$.

In Fig. 5, it can be seen that the addition of previous day's SI increases the adjusted coefficient of determination to 1 (more precisely $\geq 0.9992$ ) throughout the entire column, making the 3-predictor linear model a very good representation of the response (the lines are not distinguishable from the vertical axis on the graph). As expected, the intercept term does not change from the 2-predictor results. From the standardised regression coefficients, it can be seen that the current day's SI remains unchanged by the addition of the extra predictor. In contrast, the memory has now less of an importance above $35 \mathrm{~km}$ and becomes negligible above $45 \mathrm{~km}$. This contribution is now taken over by the previous day's SI, which relative contribution peaks around $41 \mathrm{~km}$. The nonnormalised memory has a slightly smaller peak, about one to two kilometres lower in altitude. The previous day's SI peaks around $40 \mathrm{~km}$, similarly to the current day's SI, but with a magnitude three times smaller. This much lower magnitude suggests that this two-time level scheme for the SI term is accurate enough to include most chemical effects and that a 


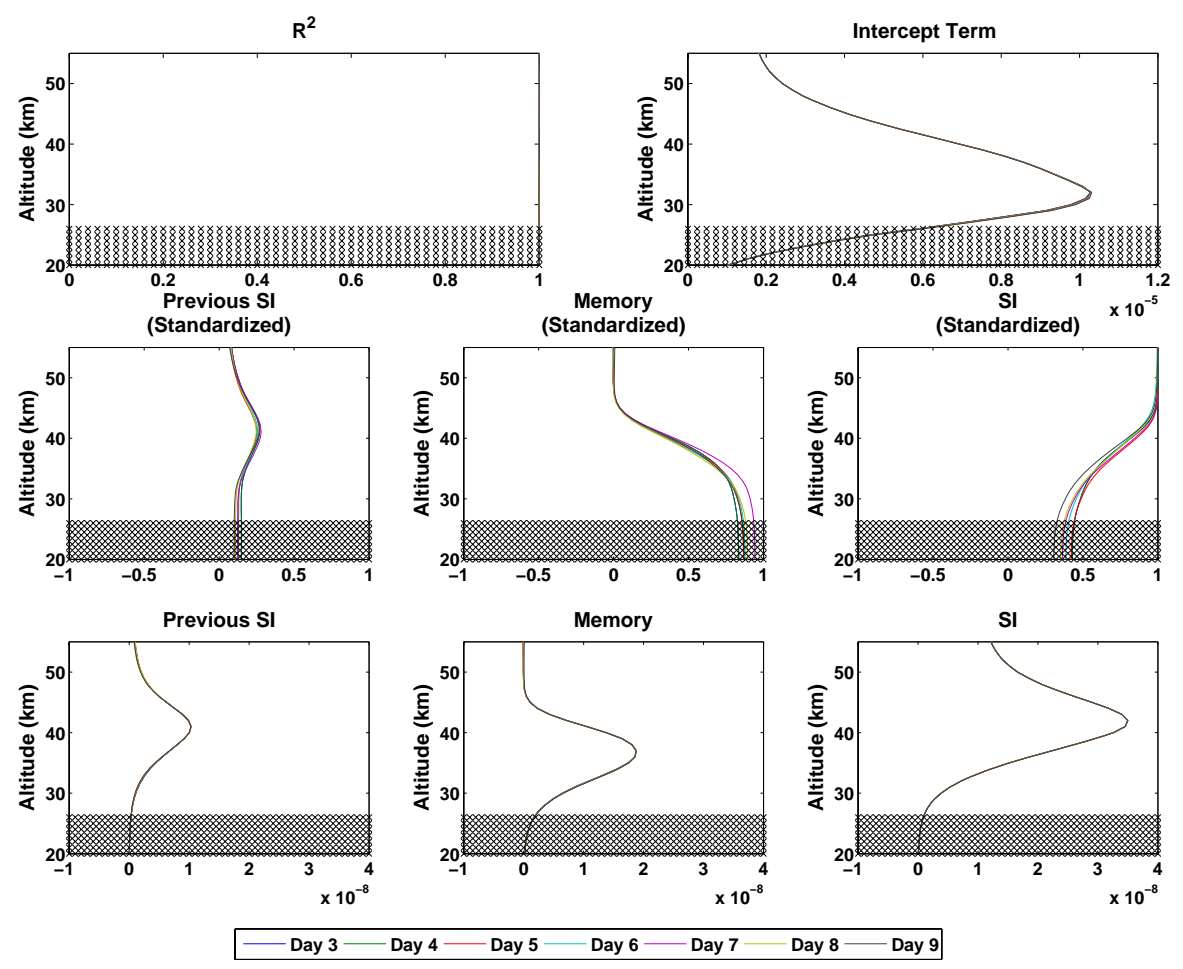

Fig. 5. Regression coefficients for the 3-predictor autoregressive model for simulation days 3 to 9 (different colours). Top row: adjusted coefficient of determination $\bar{R}^{2}$ (left) and intercept term $\alpha^{\prime}=\bar{y}$ (right). Middle row: standardised previous day's solar irradiance term $\delta$ (left), standardised memory term $\beta$ (middle) and standardised solar irradiance term $\gamma$ (right). Lower row: non-normalised previous day's solar irradiance term $\delta^{\prime}$ (left), memory term $\beta^{\prime}$ (middle) and solar irradiance term $\gamma^{\prime}$ (right). Regions where the standard deviation (amongst the ensemble) in the observed variable $y$ was smaller than $5 \%$ of the maximum standard deviation in the column are hatched out.

three-time level scheme is unnecessary (as confirmed by the adjusted coefficient of determination).

The day-to-day variability of the non-normalised regression coefficients is insignificant for both the 2- and 3predictor models. This is seen on Figs. 4 and 5 by the fact that all lines of different colours overlap and can not be distinguished from each other. There is only substantial day-today variability in the standardised coefficients below $40 \mathrm{~km}$, where the overall response is small, due to the magnifying effect of the decreasing $\sigma_{y}$ at lower altitudes. Hence, it appears that the results are robust to the changes in chemical conditions over the 10 days of the simulations.

\subsection{Sensitivity to initial conditions and temperature}

In order to understand how the initial conditions affect the chemical response to solar perturbations, additional multiple linear regressions were performed on simulations with perturbed initial conditions (Fig. 1). The chemical response of $\mathrm{O}_{\mathrm{x}}$ was found to be sensitive to perturbations in the temperature, while it showed no significant sensitivity to perturbations in $\mathrm{H}_{2} \mathrm{O}, \mathrm{NO}_{\mathrm{x}}$ or $\mathrm{O}_{\mathrm{x}}$ (not shown).

Figure 6 shows the sensitivity to temperature of the nonnormalised regression coefficients for the current day's SI and the memory from the 3-predictor model. The previous day's SI coefficient showed the same sensitivity to temperature as the current day's SI, but since its effect is both similar and of a much lesser magnitude, it was not deemed useful to show. The 2-predictor model's sensitivity (not shown) was similar to the 3-predictor model. For both coefficients in Fig. 6, a shift towards lower altitudes is observed for increasing temperatures, accompanied by a weakening of the effect. The variability of the response with the day of the simulation is insignificant, with all lines overlapping each other. A similar result was found in the observational analysis by Fioletov (2009), such that the ozone response weakened for a temperature disturbance in phase with the solar variation. Brasseur (1993) and Keating et al. (1994) also found that an increase in upper stratospheric temperatures resulted in increased rates of ozone destruction, accompanied with a weaker ozone response to solar variability. This is explained by the temperature dependence of the $\mathrm{NO}_{\mathrm{x}}$ catalytic cycle, which leads to larger $\mathrm{O}_{\mathrm{x}}$ concentrations, and consequently a larger response to solar variability, at lower temperatures.

It is interesting to contrast the significant effect of the temperature perturbation with the insignificant effect of the $\mathrm{NO}_{x}$ perturbation. These perturbations are meant to be representative of the natural variability across seasons and longitudes 


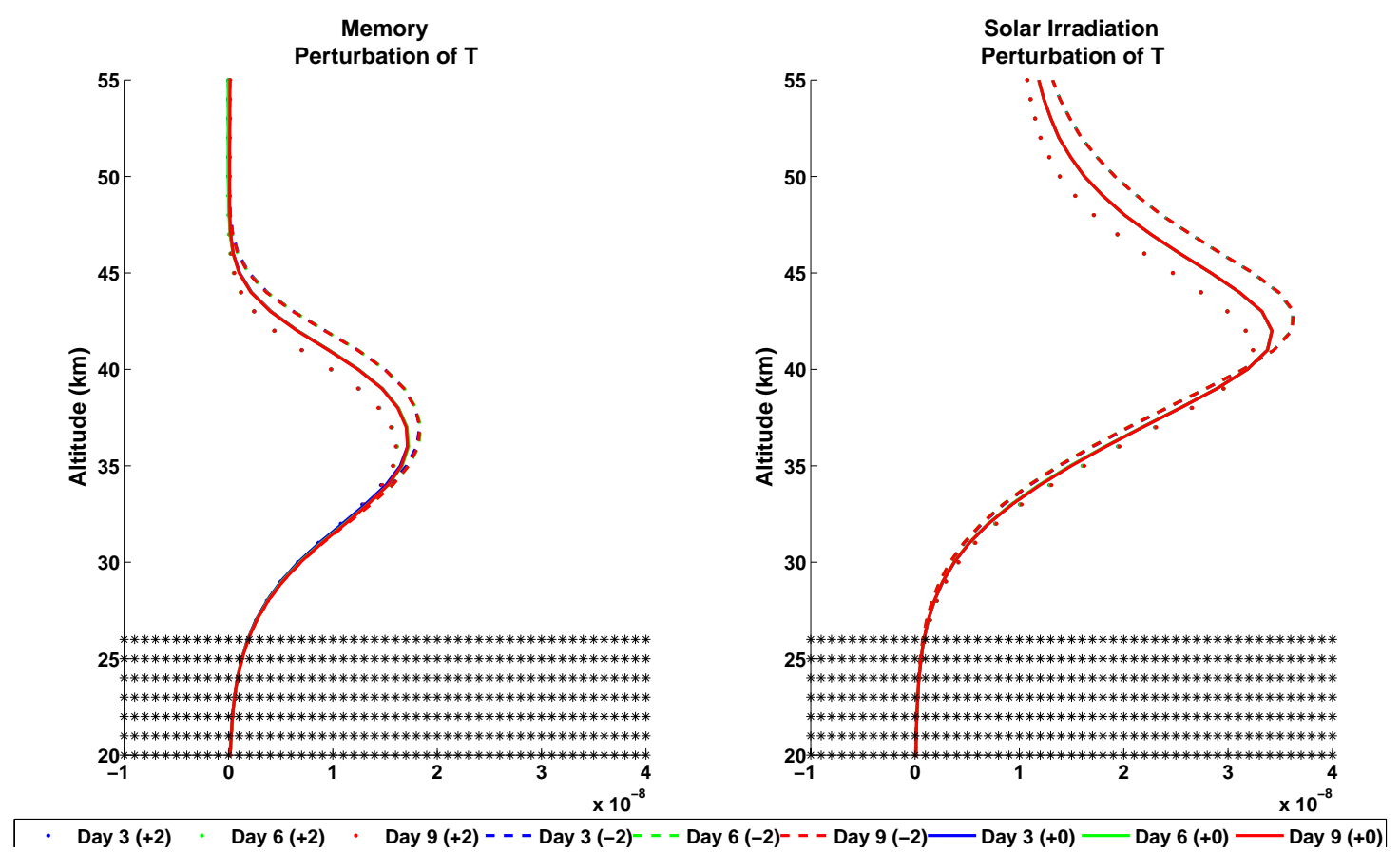

Fig. 6. Sensitivity to temperature of the non-normalised regression coefficients for the memory $\beta^{\prime}$ (left) and current day's solar irradiance $\gamma^{\prime}$ (right) for the 3-predictor model. The solid line repeats results from the regular simulation (Fig. 5), and the dashed and dotted lines are for a temperature perturbed with minus and plus two standard deviations, respectively (see Fig. 1). Different colours indicate different simulation days. Note that the previous day's solar irradiance coefficient (not shown) has a similar sensitivity to temperature as the current day's solar irradiance, and that the 2-predictor model's coefficients (not shown) have a similar sensitivity to the corresponding ones in the 3-predictor model. Regions where the standard deviation (amongst the ensemble) in the observed variable $y$ was smaller than $5 \%$ of the maximum standard deviation in the column are hatched out.

at the equator, and the variability of $\mathrm{NO}_{\mathrm{x}}$ appears to be too small to be felt on odd oxygen. However, variability in $\mathrm{NO}_{\mathrm{x}}$ related to either anthropogenic emissions of $\mathrm{N}_{2} \mathrm{O}$ or to different latitudes, may be larger than that used here. A subsequent generalisation of the statistical model to various latitudes and atmospheric compositions will need to include the effect of $\mathrm{NO}_{\mathrm{x}}$ as well as temperature.

\subsection{Evaluation of the error of the statistical models}

As shown in Sect. 4.1, the 2- and 3-predictor models fit the ensemble simulations with a good and excellent accurary, respectively. In this section, we perform an independent evaluation of their skills at representing the effect of solar variability on ozone. For this purpose, we use a new, independent pseudo-random solar variability sequence, started after the end of the one used for the regression. As described in Sect. 2.2, these statistical models can be used either off-line or on-line with the photochemical model (or similarly with a CCM). In the off-line mode, the statistical model takes care of the effect of the solar variability while the photochemical model simulates solar average conditions. The statistical model does not feed back into the photochemical model. While this mode provides the most direct evaluation of the predictive skills of the statistical models, it may not be appropriate when the feed back between radiation and photochemistry needs to be accurately resolved. In the online mode, the ozone perturbation generated by the statistical model is added to the ozone concentration in the photochemistry scheme when initialising the latter for the next day's calculation. However, since the photochemical model is initialised every day with the perturbed ozone concentration, it keeps memory of the previous day's perturbation in ozone. Thus, the memory term in the statistical model (Eq. 8) must be dropped in this mode, giving rise to potential additional errors.

Figure 7 shows the error in the two statistical models for the two modes of coupling with the photochemical model. The bias and RMS errors are estimated here using, respectively, the relative mean difference and the relative root mean square difference of the diurnal average ozone concentrations between the off/on-line and the control experiments. The control experiment is an ensemble of simulations where the solar variability is resolved by the photochemical model. The errors are relative to the ozone response in the sense that they are normalised by the root mean square difference between the control and the solar average experiments. Since the control experiment is centred around the solar average 


\section{Relative Mean Difference}

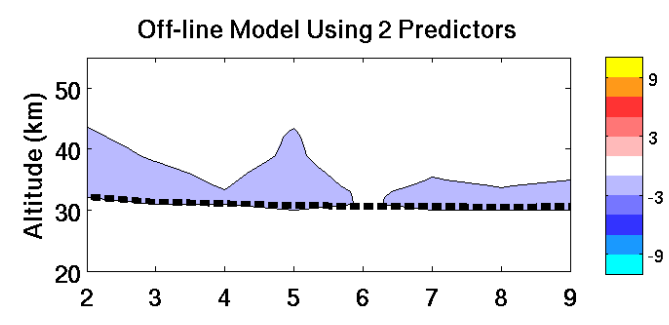

Off-line Model Using 3 Predictors

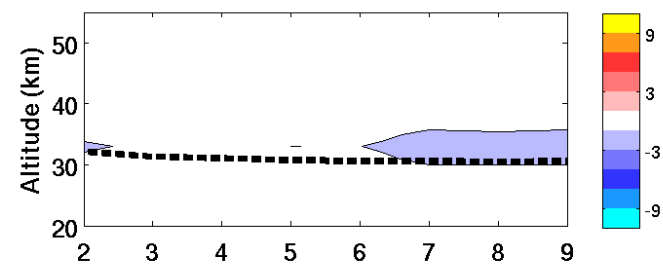

On-line Model Using 2 Predictors

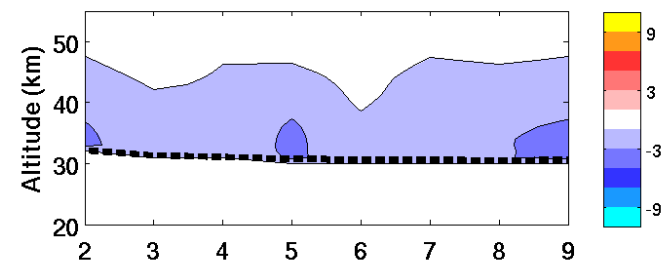

On-line Model Using 3 Predictors

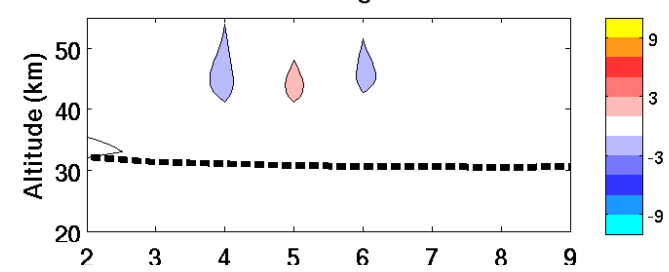

Relative RMS Difference
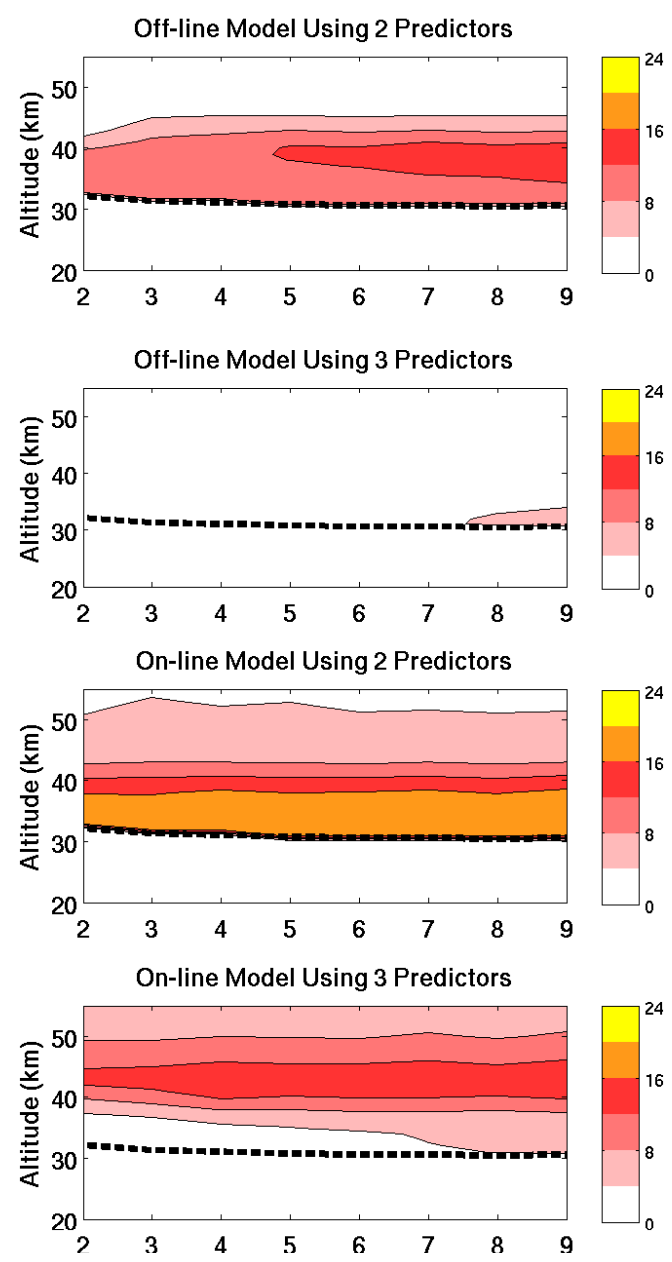

Fig. 7. Errors in percents of the statistical model when used off-line or on-line to predict the ozone perturbation due to solar variability in an independent set of experiments, as a function of simulation day (horizontal axis) and altitude (vertical axis). The left column indicates the relative bias in the statistical model, calculated as the mean difference between solar variability simulations with the statistical model used off/on-line and the control experiment, divided by root mean square difference between the control and the solar average experiments. The right column indicates the relative error of the statistical model, calculated as the root mean square difference between solar variability simulations with the statistical model used off/on-line and the control experiment, divided by root mean square difference between the control and the solar average experiments. Below the thick black dashed line lies the region where no calculation is made because the denominator is smaller than one thousands of the solar average ozone concentration.

simulation, the normalisation factor is equal to the standard deviation of the solar variability effect in the ozone concentration $\left(\sigma_{y}\right)$. In the regions where this normalisation factor (i.e. the ozone response) is smaller than one thousands of the solar average ozone concentration, the response and errors are set to zero (areas under the thick dashed lines in Fig. 7). This cut-off assumes that ozone responses smaller than $0.1 \%$ can be neglected in a model.

As expected, the bias and RMS errors are smaller in the 3 -predictor than in the 2-predictor model, and are smaller in the off-line mode than in the on-line mode. In the best case, the off-line 3-predictor model offers an excellent accuracy throughout the stratosphere with a bias smaller than
$2 \%$ and an RMS error smaller than 5\%. In the worst case, the on-line 2-predictor model still offers a reasonable accuracy with a bias smaller than $5 \%$ and an RMS error smaller than $20 \%$. This accuracy in the on-line mode is improved by the addition of one predictor to a bias smaller than $1 \%$ and an RMS error smaller than $15 \%$. This absence of a systematic bias in the 3-predictor model when used on-line makes it an excellent candidate for a CCM. Note furthermore that, in contrast to the on-line 2-predictor model, the on-line 3-predictor model sees its relative error increasing at altitudes above $40 \mathrm{~km}$, where the ozone response weakens. Hence, the absolute error in the on-line 3-predictor model is markedly smaller than in the on-line 2-predictor model. 

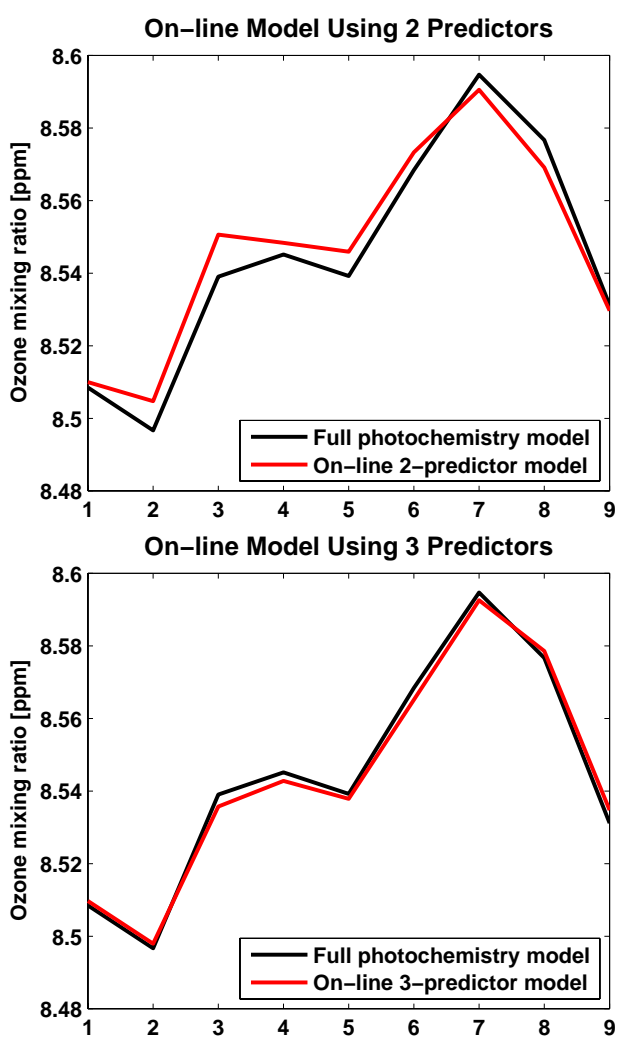

Fig. 8. Illustration of the performance of the statistical model when used on-line for days 1 to 9 at $37 \mathrm{~km}$ altitude, for a member simulation chosen randomly in the ensemble used in Fig. 7. Black: ozone mixing ratio from the control simulation. Red: ozone mixing ratio with the solar variability represented by the 2-predictor model (top) and the 3-predictor model (bottom).

The time variation of errors is small in all cases, confirming the low sensitivity of the statistical models to the chemical changes that occur over the 10 day simulations. The performance of the statistical models, when used on-line, is illustrated in Fig. 8 for a randomly choosen member of the ensemble of 200 simulations at $37 \mathrm{~km}$, the altitude where the ozone response is largest. Overall, the two statistical models provide an accurate, computationally inexpensive representation of the effect of solar variability on ozone, with the 3 -predictor model being the most accurate.

\subsection{Magnified solar variability}

The Lean (1997) solar minimum and maximum spectra used in this study are reconstructions based on different proxies and are subject to large uncertainties. Haigh et al. (2010) showed that observed spectra from the Spectral Irradiance Monitor (SIM) and the Solar Stellar irradiance Comparison Experiment (SOLSTICE) instruments on satellite SORCE (Harder et al., 2005) differ very significantly from the Lean (1997) spectra for the period 2004 to 2007 , with variability larger by factors of four to six in the range 200 to $400 \mathrm{~nm}$, and an inversed variability between 400 and $700 \mathrm{~nm}$. Although it is beyond the scope of this paper to apply the method developed here to these new observations, we present additional experiments in this section that illustrate the sensitivity of the ozone response to differences in the SSI variability pattern.

Figure 9 (top left) shows the results from additional pairs of simulations using the comprehensive photochemistry model with the departure between solar maximum and minimum spectra and the reference solar average spectrum magnified uniformly by a factor between 0.1 and 3.0. The response is linearly proportional to the magnitude of the solar change within this range (all lines and symbols overlap to each other). Increasing beyond the factor 3.0 was attempted but led to instability of the photochemical model. This linearity allows the statistical models developed here, and in particular the 3-predictor model, to capture the response to solar variability, even when magnified by a factor three, with an excellent accuracy throughout the stratosphere, as confirmed in Fig. 9 (top right). In the latter panel, results from the 3predictor model (small symbols) overlap with those from the photochemical model (colour lines). The 2-predictor model gives results that are slightly high biased (large symbols).

Figure 9 (bottom) shows the responses in the photochemical and statistical models as a function of the magnifying factor at $37 \mathrm{~km}$ altitude. Consistently, results from the 3 -predictor model (red symbols) overlap with those from the photochemical model (dark blue line), whereas the 2predictor model (green symbols) is slightly high biased. These results are compared on Fig. 9 (bottom) with the response found in the photochemical model when the magnifying factor is applied only within the range 200 to $400 \mathrm{~nm}$. In the latter case, the response remains linear through the entire range but with a smaller slope and non-zero intercept. This is explained by the ozone production outside the 200 to $400 \mathrm{~nm}$ window which is kept constant in these experiments.

\section{Conclusions}

This paper proposes a simplified modelling framework for characterising the effect of spectral solar irradiance variability on the stratosphere, focussing on the pure photochemical response. First, the solar maximum-minimum response is analysed and compared with past studies. The solar maximum-minimum response in $\mathrm{O}_{\mathrm{x}}$ (i.e. ozone) shows a sharp peak of 0.18 ppmv (about $3 \%$ ) increase in $\mathrm{O}_{\mathrm{x}}$ around $37 \mathrm{~km}$ altitude and a rapid decrease of this response towards lower altitudes with a near-zero response below $27 \mathrm{~km}$ altitude. This pattern compares particularly well with estimates from Fioletov (2009) based on satellite observations of the 27-day cycle combined with the $\mathrm{Mg}$ II index (the orange lines in their Fig. 9). In Climate-Chemistry Models, the ozone response to the 27-day cycle shows a smoother peak which typically extends at lower altitudes, and the response stays significant, though very variable, at altitudes even lower than 

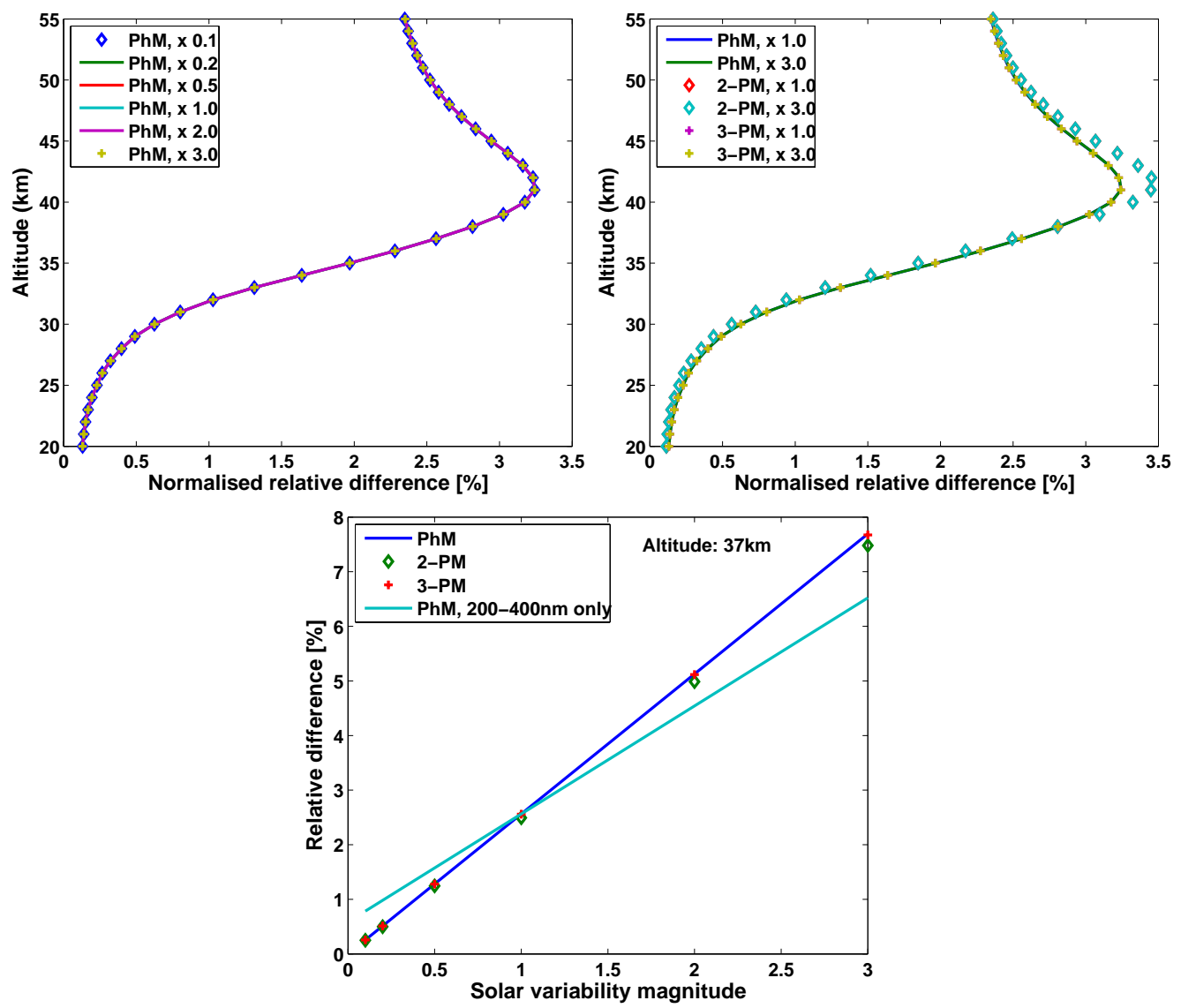

Fig. 9. Normalised relative difference in $\mathrm{O}_{\mathrm{x}}$ concentration between solar maximum and solar minimum experiments for various solar variability magnitudes. The relative difference is calculated as the solar maximum-minimum difference divided by the $\mathrm{O}_{\mathrm{x}}$ concentration, and normalised by the solar variability magnitude. A solar variability magnitude of one corresponds to Lean (1997) solar maximum and minimum spectra. Top left: photochemical model (PhM) with solar variability magnitudes from 0.1 to 3.0. Top right: photochemical model, 2-predictor model (2-PM) and 3-predictor model (3-PM) with solar variability magnitudes 1.0 and 3.0. Bottom: normalised relative difference at $37 \mathrm{~km}$ altitude as a function of the solar variability magnitude for the photochemical model and the 2- and 3-predictor models. In addition, the light blue line shows the response of the photochemical model with the solar variability magnified with respect to Lean (1997) only in the range $200-400 \mathrm{~nm}$.

$20 \mathrm{~km}$ (e.g. Austin et al., 2007). Assuming that the CCMs achieve a similar photochemical response as here, this difference can come either from the effect of coupling photochemistry with radiation and dynamics, or from errors in the statistical separation between the solar impact and the dynamical variability. The response in other chemical families is also discussed and is consistent with past studies (Egorova et al., 2005). It was found that $\mathrm{HO}_{\mathrm{x}}$ increased in the upper stratosphere-lower mesosphere up to $2 \%$ and limited the increase in $\mathrm{O}_{\mathrm{x}}$ in this region. $\mathrm{NO}_{\mathrm{x}}$ was found to increase during the day below $40 \mathrm{~km}$ by $1 \%$, and $\mathrm{Cl}_{\mathrm{x}}$ was found to increase during the day above $35 \mathrm{~km}$ altitude, with a peak of $1 \%$ at $40 \mathrm{~km}$.

Second, an ensemble simulation approach is taken together with regression analysis to develop a complete characterisation of the $\mathrm{O}_{\mathrm{x}}$ response to SSI variability. Ensemble simulations are performed using daily pseudo-random sequences of solar variability. The $\mathrm{O}_{\mathrm{x}}$ response is then regressed following two auto-regressive models with 2- and 3 -predictors. The two predictors common to the two models, are the previous day's ozone concentration and the current day's solar irradiance. The additional predictor in the 3 -predictor model is the previous day's solar irradiance. The regression leads to coefficients of determination larger than 0.97 and 0.9992 , respectively. The relative contribution of the current day's SI is found to dominate above $40 \mathrm{~km}$, while the memory dominates below $40 \mathrm{~km}$ and remains non-zero in the upper stratosphere. In the 3-predictor model, the relative contribution of the previous day's SI peaks at $40 \mathrm{~km}$ and takes over the upper-stratospheric contribution of the memory term. The sensitivity of the regression coefficients is analysed with respect to initial concentrations of $\mathrm{H}_{2} \mathrm{O}$ (i.e. $\mathrm{HO}_{\mathrm{x}}$ ), $\mathrm{NO}_{\mathrm{x}}, \mathrm{O}_{\mathrm{x}}$ and the temperature. The results are found to be sensitive to the temperature only, with a shift of the peak towards 
lower altitudes accompanied by a weakening of the magnitude of the non-normalised regression coefficients. This sensitivity is attributed to the temperature dependence of the $\mathrm{NO}_{\mathrm{x}}$ catalytic cycle.

The two regression models are also evaluated when used as proxy models for the prediction of the ozone response to solar variability. For this purpose, they are coupled off/on-line with a photochemical model representing the solar average chemistry. The bias and RMS errors are estimated relative to the ozone response. As expected, errors are larger in the 2than in the 3-predictor model, and in the on-line than in the off-line mode. When used on-line, the memory term must be dropped from the model since it is carried over by the photochemistry model itself. This is expected to introduce an additional error. Nevertheless, when used on-line the 2and the 3-predictor models have a bias smaller than $5 \%$ and $1 \%$, respectively, and an RMS error smaller than $20 \%$ and $15 \%$, respectively. This makes the on-line 3-predictor model an interesting candidate for a simple, fast parameterisation representing the effect of solar variability in the stratosphere. The linearity of the $\mathrm{O}_{\mathrm{x}}$ response, and thereby the validity of the statistical models, in an extended domain of solar variability was tested with solar maximum and solar minimum experiments. It was found that within the range tested here, extending the solar variability magnitude of Lean (1997) by a factor three uniformly through the spectrum, the response remains fully linear and the statistical models identical. In contrast, magnifying the solar variability within a limited range of wavelengths from 200 to $400 \mathrm{~nm}$ led to a different linear relationship between response and solar variability magnitude.

The modelling approach presented here based on ensembles of transient photochemical simulations with linear regression analysis sets a simple framework to characterise the effect of SSI variability on stratospheric chemistry. In particular, it is proposed as an efficient framework which can be used to evaluate the implications on the stratosphere of using more complex SSI variability patterns as the still commonly used one based upon Lean (1997) solar maximum/minimum spectra. These include spectral time series from SIM or SOLSTICE, advanced reconstructions (e.g. Thuillier et al., 2012) or outputs from semi-empirical solar models (e.g. Bolduc et al., 2012). Haigh et al. (2010) suggest, based upon recent results from instruments SIM and SOLSTICE onboard satellite SORCE, that the variability in the ultra-violet range from 200 to $400 \mathrm{~nm}$ may be underestimated by a factor 4 to 6 in Lean (1997). As shown in the present study, while the ozone response remains linear with a factor three applied uniformly through the spectrum, it changes if the factor three is only applied to the 200 to $400 \mathrm{~nm}$ range. This illustrates the dependence of the ozone response to the particular wavelengths forced, including those outside the 200 to $400 \mathrm{~nm}$ range which dominates stratospheric photolysis processes. Furthermore, it is expectable that variable correlations between pairs of wavelengths through the spectrum will affect the ozone response. In particular, Bolduc et al. (2012) suggest that the pair of wavelengths 240 and $300 \mathrm{~nm}$ may have a correlation well below 1.0 , which may specially affect the stratospheric chemistry through a decorrelation of photolysis processes for $\mathrm{O}_{2}$ and $\mathrm{O}_{3}$. CCMs are unquestionably necessary to study the interactions between photochemistry and dynamics in the stratosphere. However, in the current context where various data sets, reconstructions and empirical models of SSI variability need to be inter-compared with respect to their implications on stratosphere, a modelling framework such as the one proposed here presents two major advantages, aside from its minimal computational cost. First, it provides a complete picture of the SSI response, including its non-stationary component. CCM studies typically only include the statistically stationary component of the response to solar variability as a result of the necessity to perform temporal averages to remove the large unforced variability. Second, it provides a well-constrained and robust response. Here again, the large unforced variability present in CCM outputs limits the robustness of the results and may interfere with them where feed-back between photochemistry and dynamics are present. In addition, differences in the dynamical behaviour of different CCMs may affect their results and ranges of responses.

This modelling framework can be easily extended to study the feed-back between photochemistry and temperature. A next step would be to allow the temperature to change according to the response of ozone by incorporating an interactive radiation calculation in the column forced with solar average. A further step would be to include SSI variability in the radiation calculation. This would allow to evaluate the importance of these two levels of feed-back on the ozone response to solar variability and results could be compared with Semeniuk et al. (2011) and Gruzdev et al. (2009).

Finally, the regression models resulting from this study offer an accurate, inexpensive approach for parameterising the effect on stratospheric ozone of SSI variability in CCMs. In this study, the regression models are based upon the simple Lean (1997) solar maximum/minimum spectra. However, employing the same method, other regression models can be constructed for other SSI variability patterns. They can be extended to other seasons, latitudes, for a range of temperatures, and possibly to take into account long-term compositional changes. It is important to note that since the memory contribution has to be taken over by the photochemical module of the CCM, it is necessary to build the regression model using a photochemical model which is consistent to that of the CCM. Further work would be necessary in this direction. Here, we limit ourselves to proposing the approach and it is beyond the scope of this paper to present an end-user parameterisation. 
Acknowledgements. Kirill Semeniuk is thanked for providing the data used in the initial conditions of the simulations. We acknowledge the Fonds Québequois de Recherche sur la Nature et les Technologies (FQRNT) for funding this study through the Team Grant program. Two anonymous reviewers are thanked for their helpful comments.

Edited by: A. J. G. Baumgaertner

\section{References}

Austin, J., Hood, L. L., and Soukharev, B. E.: Solar cycle variations of stratospheric ozone and temperature in simulations of a coupled chemistry-climate model, Atmos. Chem. Phys., 7, 16931706, doi:10.5194/acp-7-1693-2007, 2007.

Bolduc, C., Charbonneau, P., Bourqui, M. S., and Crouch, A.: A fast model for the reconstruction of spectral solar irradiance in the near- and mid-ultraviolet, Sol. Phys., in-press, 2012.

Brasseur, G.: The response of the middle atmosphere to longterm and short-term solar variability: a two-dimensional model, J. Geophys. Res., 98, 23079-23090, doi:10.1029/93JD02406, 1993.

Brasseur, G., De Rudder, A., Keating, G. M., and Pitts, M. C.: Response of middle atmosphere to short-term solar ultraviolet variations: 2. Theory, J. Geophys. Res., 92, 903-914, 1987.

Brasseur, G., Walters, S., Hitchman, M. H., Dymek, M., Falise, E., and Pirre, M.: An interactive chemical dynamical radiative twodimensional model of the middle atmosphere, J. Geophys. Res., 95, 5639-5655, 1990.

Chabrillat, S. and Fonteyn, D.: Modelling long-term changes of mesospheric temperature and chemistry, Adv. Space Res., 32, 1689-1700, doi:10.1016/S0273-1177(03)90464-9, 2003.

Chabrillat, S. and Kockarts, G.: Simple parameterization of the absorption of the solar Lyman-alpha line, Geophys. Res. Lett., 24, 2659-2662, 1997.

Damian, V., Sandu, A., Damian, M., Potra, F. A., and R., C. G.: The Kinetic PreProcessor KPP. A Software Environment for Solving Chemical Kinetics, Comput. Chem. Eng., 26, 1567-1579, 2002.

DeLand, M.T., Cebula, R.P.: Creation of a composite solar ultraviolet irradiance data set, J. Geophys. Res., 113, A11103, doi:10.1029/2008JA013401, 2008.

DeLand, M. T. and Cebula, R. P.: Composite MG-II solar activity index for solar cycle-21 and cycle-22, J. Geophys. Res., 98, 12809-12823, doi:10.1029/93JD00421, 1993.

Dessler, A. E.: The chemistry and physics of stratospheric ozone, International Geophysics Series, Vol. 74, Academic Press, USA, 214 pp., 2000.

Egorova, T.: Modeling the effects of short and long-term solar variability on ozone and climate, Ph.D. thesis, Swiss Federal Institute of Technology Zurich, 2005.

Egorova, T., Rozanov, E., Manzini, E., Haberreiter, M., Schmutz, W., Zubov, V., and Peter, T.: Chemical and dynamical response to the 11-year variability of the solar irradiance simulated with a chemistry-climate model, Geophys. Res. Lett., 31, 1-4, 2004.

Egorova, T., Rozanov, E., Zubov, V., Schmutz, W., and Peter, T.: Influence of solar 11-year variability on chemical composition of the stratosphere and mesosphere simulated with a chemistryclimate model, Adv. Space Res., 35, 451-457, 2005.
Errera, Q., Daerden, F., Chabrillat, S., Lambert, J. C., Lahoz, W. A., Viscardy, S., Bonjean, S., and Fonteyn, D.: 4D-Var assimilation of MIPAS chemical observations: ozone and nitrogen dioxide analyses, Atmos. Chem. Phys., 8, 6169-6187, doi:10.5194/acp8-6169-2008, 2008.

Fioletov, V. E.: Estimating the 27-day and 11-year solar cycle variations in tropical upper stratospheric ozone, J. Geophys. Res., 114, D02302, doi:10.1029/2008JD010499, 2009.

Fleming, E., Chandra, S., Jackman, C., Considine, D., and Douglass, A.: The middle atmospheric response to short and long term solar UV variations: Analysis of observations and 2D model results, J. Atmos. Sol.-Terr. Phy., 57, 333-365, 1995.

Gruzdev, A. N., Schmidt, H., and Brasseur, G. P.: The effect of the solar rotational irradiance variation on the middle and upper atmosphere calculated by a three-dimensional chemistry-climate model, Atmos. Chem. Phys., 9, 595-614, doi:10.5194/acp-9595-2009, 2009.

Haigh, J., Winning, A. R., Toumi, R., and Harder, J. W.: An influence of solar spectral variations on radiative forcing of climate, Nature, 467, 696-699, doi:10.1038/nature09426, 2010.

Haigh, J. D.: The role of stratospheric ozone in modulating the solar radiative forcing of climate, Nature, 370, 544-546, 1994.

Hairer, E. and Wanner, G.: Solving Ordinary Differential Equations II. Stiff and differential-algebraic problems, Vol. 14 of Springer series in computational mathematics, Springer, 2nd edn., 1996.

Harder, J. W., Fontenla, J. M., Pilewskie, P., Richard, E. C., and Woods, T. N.: Trends in solar spectral irradiance variability in the visible and infrared, Geophys. Res. Lett., 36, L07801, doi:10.1029/2008GL036797, 2009.

Harder, J., Fontenla, J., White, O., Rottman, G., and Woods, T.: Solar spectral irradiance variability comparisons of the SORCE SIM instrument with monitors of solar activity and spectral synthesis, in: Solar Variability and Earth's Climate, Book Series: Mem. Soc. Astron. Ital., 76, 735-742, 2005.

Hedin, A.: Extension of the MSIS thermosphere model into the middle and lower atmosphere, J. Geophys. Res., 96, 1159-1172, doi:10.1029/90JA02125, 1991.

Intergovernmental Panel of Climate Change, WGI: Climate Change 2007: The Physical Science Basis, Summary for Policy Makers, Contribution of Working Group I to the Fourth Assessment Report of the Intergovernmental Panel on Climate Change, 2007.

Keating, G., Brasseur, G., Chiou, L., and Hsu, N.: Estimating 11year solar UV variations using 27-day response as a guide to isolate trends in total column ozone, Adv. Space Res. Oxford, 14, 199-199, 1994.

Khosravi, R., Brasseur, G., Smith, A., Rusch, D., Walters, S., Chabrillat, S., and Kockarts, G.: Response of the mesosphere to human-induced perturbations and solar variability calculated by a 2-D model, J. Geophys. Res., 107, 4358, doi:10.1029/2001JD001235, 2002.

Lean, J. L.: Detection and parameterization of variations in solar mid-and near-ultraviolet radiation (200-400 nm), J. Geophys. Res., 102, 29939-29956, doi:10.1029/97JD02092, 1997.

Merkel, A. W., Harder, J. W., Marsh, D. R., Smith, A. K., Fontenla, J. M., and Woods, T. N.: The impact of solar spectral irradiance variability on middle atmospheric ozone, J. Geophys. Res., 38, L13802, doi:10.1029/2011GL047561, 2011.

Rozanov, E., Egorova, T., Frohlich, C., Haberreiter, M., Peter, T., and Schmutz, W.: Estimation of the ozone and temperature sen- 
sitivity to the variation of spectral solar flux, European Space Agency-Publications-ESA SP, 508, 181-184, 2002.

Rozanov, E., Egorova, T., Schmutz, W., and Peter, T.: Simulation of the stratospheric ozone and temperature response to the solar irradiance variability during sun rotation cycle, J. Atmos. Sol.Terr. Phy., 68, 2203-2213, 2006.

Rozanov, E. V., Schlesinger, M. E., Egorova, T. A., Li, B., Andronova, N., and Zubov, V. A.: Atmospheric response to the observed increase of solar UV radiation from solar minimum to solar maximum simulated by the University of Illinois at Urbana-Champaign climate-chemistry model, J. Geophys. Res., 109, D01110, doi:10.1029/2003JD003796, 2004.

Sander, S. P., Friedl, R. R., Ravishankara, A. R., Golden, D. M., Kolb, C. E., Kurylo, M. J., Molina, M. J., Moortgat, G. K., KellerRudek, H., Finlayson-Pitts, B. J., Wine, P. H., Huie, R. E., and Orkin, V. L.: Chemical Kinetics and Photochemical Data for Use in Atmospheric Studies - Evaluation Number 15, JPL Publication, 06-2, 2006.

Sander, S. P., Friedl, R. R., Abatt, J., Barker, J. R., Burkholder, J. B., Golden, D. M., Kolb, C. E., Kurylo, M. J., Moortgat, G. K., Wine, P. H., Huie, R. E., and Orkin, V. L.: Chemical Kinetics and Photochemical Data for Use in Atmospheric Studies - Evaluation Number 16, JPL Publication, 09-31, 2010.

Semeniuk, K., Fomichev, V. I., McConnell, J. C., Fu, C., Melo, S. M. L., and Usoskin, I. G.: Middle atmosphere response to the solar cycle in irradiance and ionizing particle precipitation, Atmos. Chem. Phys., 11, 5045-5077, doi:10.5194/acp-11-50452011, 2011.

Shindell, D., Rind, D., Balachandran, N., Lean, J., and Lonergan, P.: Solar cycle variability, ozone, and climate, Science, 284, 305308, doi:10.1126/science.284.5412.305, 1999.

Soukharev, B. and Hood, L.: Solar cycle variation of stratospheric ozone: Multiple regression analysis of long-term satellite data sets and comparisons with models, J. Geophys. Res., 111, D20314, doi:10.1029/2006JD007107, 2006.
SPARC CCMVal, SPARC CCMVal Report on the Evaluation of Chemistry-Climate Models, edited by: Eyring, V., Shepherd, T. G., and Waugh, D. W., SPARC Report No. 5, WCRP-30, WMO/TD-No. 40, 2010.

Taylor, C. and Bourqui, M.: A new fast stratospheric ozone chemistry scheme in an intermediate general-circulation model. I: Description and evaluation, Q. J. Roy. Meteor. Soc., 131, 22252242, doi:10.1256/qj.04.18, 2005.

Thuillier, G., DeLand, M., Shapiro, A., Schmutz, W., Bolsée, D., and Melo, S. M. L.: The Solar Spectral Irradiance as a Function of the Mg ii Index for Atmosphere and Climate Modelling, Solar Physics, Sol. Phys., 245-266, doi:10.1007/s11207-011-9912-5, 2012.

Tourpali, K., Schuurmans, C., Van Dorland, R., Steil, B., and Brühl, C.: Stratospheric and tropospheric response to enhanced solar UV radiation: A model study, Geophys. Res. Lett., 30, 1231, doi:10.1029/2002GL016650, 2003.

Viscardy, S., Errera, Q., Christophe, Y., Chabrillat, S., and Lambert, J.-C.: Evaluation of Ozone Analyses From UARS MLS Assimilation by BASCOE Between 1992 and 1997, IEEE J-STARS, 3, 190-202, 2010.

Wilks, D. S.: Statistical methods in the atmospheric sciences, International Geophysics Series, Second Edn., Academic Press, USA, 646 pp., 2006.

Williams, V., Austin, J., and Haigh, J. D.: Model simulations of the impact of the 27-day solar rotation period on stratospheric ozone and temperature, Adv. Space Res., 27, 1933-1942, 2001.

WMO: Scientific Assessment of ozone depletion: 2006, World Meteorological Organisation, Global Ozone Research and Monitoring Project-Report, 50, Geneva, Switzerland, 2007.

Zhou, S., Rottman, G. J., and Miller, A. J.: Stratospheric ozone response to short-and intermediate-term variations of solar UV flux, J. Geophys. Res., 102, 9003-9011, doi:10.1029/96JD03383, 1997. 